PAGES International Project Office Bärenplatz 2

$\mathrm{CH}-3011$ Bern

Switzerland

Tel: +41313123133

Fax: +41313123168

pages@pages.unibe.ch

Layout: Christoph Kull

Circulation: 3200

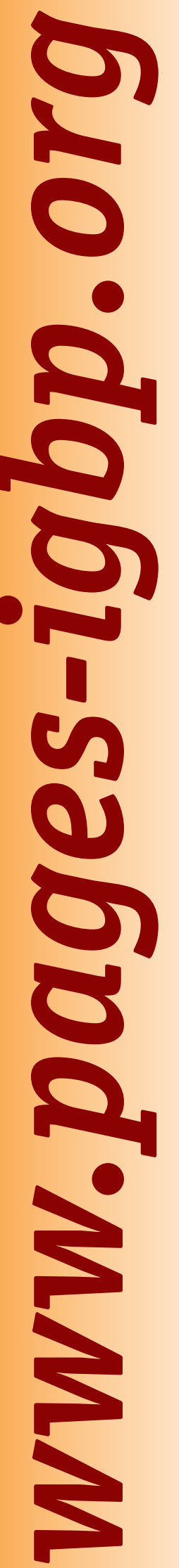

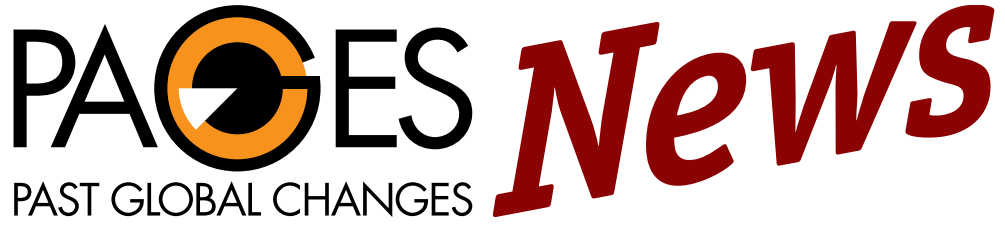

Tom Edwards Christoph Kull and Keith Alverson, Editors

Vol.10, $\mathbf{N}^{\circ} 2$ - JULY 2002

Stable Isotopes

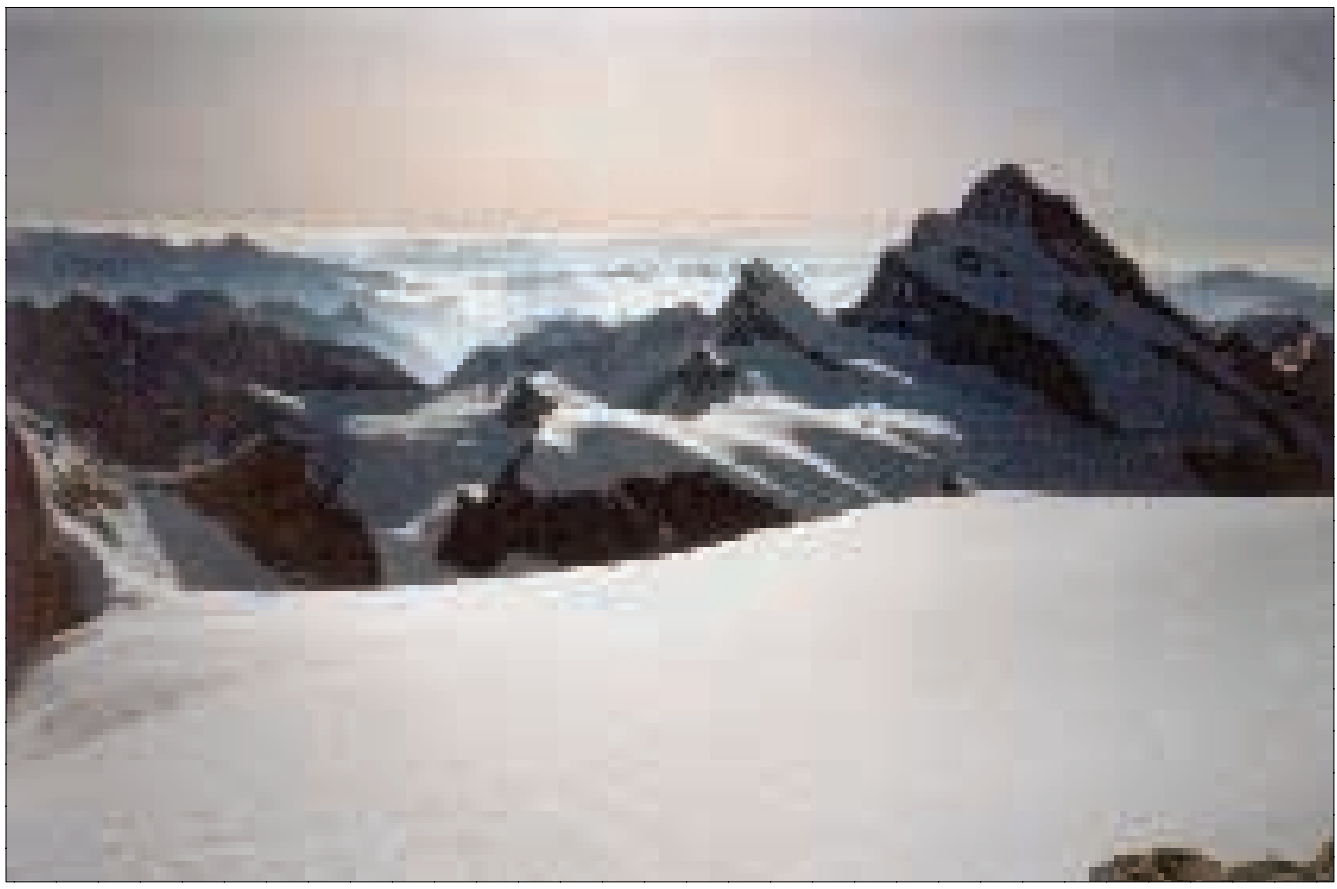

View from the Gross Fiescherhorn (4048 m) in the Swiss Alps towards the Fiescherhorn plateau $(3950 \mathrm{~m})$ in 1994. Two ice cores were drilled at this site in 1987 and 2000 (see page 6). The high peak in the background is the Finsteraarhorn (4273 m) (Photo: C. Kull).

\title{
Contents
}

2 Announcements

- Editorial: Stable Isotopes / Swiss Sojourn

- The PAGES Synthesis Project

- New on the PAGES Bookshelf

- Tales from the Field

- Inside PAGES

\section{Program News}

- NOClim: Norwegian Ocean Climate Project

\section{National Page}

- Switzerland

6 Science Highlights

- Extending Isotope in Precipitation Data Beyond Direct Measurements

- Holocene Variability in the Indian Ocean Monsoon

- Isotopic Records of Past Hydroclimatic Change

- A New Conceptual Model for Predicting Isotopic Enrichment of Lakes
- Modelling the Water Isotope Signal in the Quaternary

- Towards a Regional Synthesis of Mediterranean Climatic Change

- Past and Present Ecohydrology of the Peace-Athabasca Delta, Canada

- Lacustrine Oxygen Isotopic Records from Temperate Marl Lakes

20 Workshop Reports

- Fire-Climate Linkages in the MidLatitude Americas

- Linking the Continental Environmental Quaternary History of Southern Africa with Ocean Currents and Antarctica

- PAGES Data Board Meeting

- PAGES Meeting on High Latitude Paleoenvironments

24 Last Page

- Calendar

- Tyler and Heineken Prizes 2002 


\section{Announcements}

\section{Editorial: Stable Isotopes / Swiss Sojourn}

I am pleased to be writing this editorial at home in my Canadian office, yet I already sorely miss my colleagues and friends at the PAGES IPO, the beautiful city of Bern and the wonderful landscape of Switzerland. My fivemonth sabbatical sojourn as a PAGES visiting scientist was highly memorable and productive, and an ideal chance to network in the paleoscience community and to recharge my intellectual batteries. I warmly thank Keith, the PAGES SSC, and the entire PAGES staff for granting me this honour, and I heartily recommend that others take advantage of the same opportunity. Some may be aware of my activities as the leader of the PAGES ISOMAP initiative, dedicated to continental isotope paleoclimatology, and especially to the mapping and modelling of water isotope data from paleoprecipitation. For more information on the progress of this initiative, readers are directed to the ISOMAP link on the PAGES web site.

My more immediate responsibility as the guest editor of this Stable Isotopes issue of PAGES News was to solicit Science Highlights from workers engaged in research falling under the theme of ISOMAP. Out of an embarassment of riches, I selected eight contributions that span important aspects of the subject. The first three deal with investigations using individual continental isotopic archives, the next two with modelling of water isotope systematics at widely differing spatial and temporal scales, and the final three with ongoing multiproxy research programs in which stable isotopes play a leading role. Although necessarily providing only a glimpse of the depth and breadth of the subject, these reports clearly speak to the existence of significant opportunities for involvement and training of young researchers in a dynamic and expanding field of research. I sincerely hope they number among the readers of PAGES News.

Tom EDWards

Universitiy of Waterloo, Canada twdedwar@sciborg.uwaterloo.ca

\section{Paleoclimate, Global Change and the Future}

The PAGES synthesis project:

At this year's fall AGU PAGES will be presenting the results of our recently completed synthesis of the last decade of PAGES relevant research and seeking input for the future direction of the PAGES program.

Synthesis Book:

One of the results of the PAGES synthesis efforts is a new book Paleoclimate, Global Change and the Future due to appear in the IGBP synthesis series. The book, written by a large number of scientists from the PAGES community, will be on display, and available for purchase, at the Springer Verlag booth.

Special Session: PP12 Paleoclimate, Global Change and the Future:

Convenors: Keith Alverson, Ray Bradley and Tom Pedersen

This session will seek to draw together contributions from the full range of paleoenvironmental sciences including continental, marine and ice archives as well as the modeling community. Focus will be achieved by concentrating on those aspects of past environmental change over the past millennium, the Holocene, and Glacial/Interglacial timescales with direct relevance to future societal concerns associated with anthropogenic climate change.

Town Meeting: PAGES will hold a town meeting and icebreaker to foster an open discussion on improving U.S. community engagement with the PAGES program and to allow the AGU community to help shape how PAGES will work in the future.

For further information on the AGU Fall Meeting Information see: http://www.agu.org/meetings/fm02top.html

\section{New on the PAGES Bookshelf}

\section{Tropical Glaciers}

Georg Kaser, Henry Arthur Osmaston

(C) Cambridge University Press

December 2001 | Hardback | 228 pages

ISBN: 0521633338

orders can be directed to:

directcustserve@cambridge.org

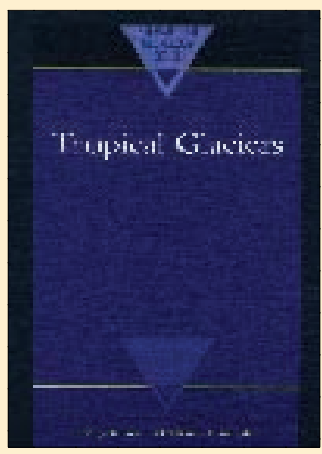




\section{The Magic Inca Glass Ball in Lake Licancabur, Chile}

Among the most fascinating features of the incredibly rich prehistoric culture of the Atacama desert are the pavements, platforms and firewood piles on the top of sacred mountains in northern Chile. These structures date from the Inca Empire and were built on volcanoes as high as or even above $6000 \mathrm{~m}$ elevation. One of the most peculiar sites is Vn Licancabur near San Pedro de Atacama with its small crater lake on top. Legend has it that this lake contains a mysterious glass ball. Using this ball as a mirror, Inka priests were able to communicate from peak to peak while smoking miracle drugs. A small expedition to discover this ball was undertaken. Among the group was the former mayor of San Pedro, a legendary archaeologist and former Miss Chile. Scuba divers hiked through a desert that has not seen much water since late-glacial times, and discovered after a few dives - what a miracle - a glass ball in the lake sediments. When the ball was brought above the water, the beams of gleaming sunlight reflected in the glass and burnt the hands of the poor diver - who dropped the ball. It then disappeared in a burst of bubbles emanating from the deep. The only remaining evidence of this unusual discovery is a black and white photograph in the art gallery in the Hotel Tulor in San Pedro showing the diver's head, the ball and a bit of water. When our expedition arrived at the hotel and expressed our plans to core the sediments of high altitude lakes in the area we were immediately engaged in a controversial debate about what we might find in our cores. The Chilean Army claims that the ball is part of a heliograph, a local artist claims that it is her gift to Mother Earth, and countless expeditions to retrieve the ball have ended without success. It is perhaps still there waiting for a joint action of PAGES-PEP1 limnologists.

\section{Martin Grosjean}

NCCR Climate, Bern, Switzerland,

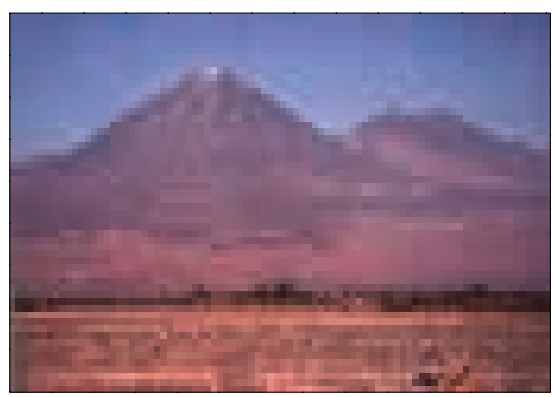

Fig. 1: Volcan Lincancabur (5930 m) seen from San Pedro de Atacama, Northern Chile (Photo: C. Kull).

Do you have an interesting and humorous story from your paleoenvironmental fieldwork? If you write it down in $\mathbf{5 0 0}$ words or less and send it to us, we will put it in PAGES news!

\section{Inside PAGES}

PAGES welcomes four new members to our Scientific Steering Committee (SSC) in 2002. Pinxian Wang is a paleoceanographer and micropaleonotologist atTongji University in Shanghai. Rick Battarbee, from University College London, is no stranger to PAGES. He joins the SSC after several years as leader of the PAGES PEP2 transect and Focus 5-LIMPACS (Human Impacts on Lake Ecosystems). Rick is a paleolimnologist. Frank Sirocko has worked in both marine and terrestrial paleoenvironmental archives including marine sedimentary records of the Asian monsoon and laminated sediments of dry maars. Finally, Olga Solomina began her SSC membership by hosting the 2002 business meeting alongside a major workshop which has served to improve Russian, and ex-soviet, pa- leoenvironmental community links with PAGES. Olga has expertise in interpreting glacial features and tree rings as indicators of Holocene climate change.

Along with welcoming these new members, PAGES thanks those members who recently stepped off the committee: Keith Briffa (UK), Patrick DeDeckker (Australia), Zhengtang Guo (China), Laurent Labeyrie (France) and Dominique Raynaud (France). Special thanks to Bruno Messerli (Switzerland), who served for many years as the Swiss Director of PAGES.

The International Project Office says goodbye to visiting scientist Tom Edwards from the University of Waterloo, Canada. Many thanks to Tom for serving as guest editor of this issue of PAGES News, convening and attending several workshops on PAGES behalf. This fall, the IPO welcomes a new guest scientist, André Paul, a paleoceanographer from the University of Bremen, Germany.

\section{Call for Contributions:}

The next issue of PAGES News will highlight the use of documentary data in paleoclimatological investigations. Science highlights that fit within this theme, as well as the usual workshop reports and program news, are welcome. If you are interested in contributing a science highlight to this issue please contact Heinz Wanner (wanner@giub.unibe.ch). Other types of contributions may be sent to Christoph Kull (kull@ pages.unibe.ch).

All submissions should follow the instructions for authors on our web-site and be submitted by October 15, 2002.

www.pages.unibe.ch/products/ newsletters.html 


\section{Program News}

\section{Norwegian Ocean Climate Project (NOClim)}

\section{SOLFRID SÆTRE HJøLlo}

NOClim scientific secretary; Solfrid.Hjollo@gfi.uib.no

Since July 2000, about 35 scientists from different disciplines have been working within the Norwegian Ocean Climate Project (NOClim), a project initiated to study ocean climate variability in the northern seas. The program focuses on theory and modelling of meridional oceanic heat transport and analysis of past and modern ocean climate process variability. The overall objectives of NOClim are to improve our understanding of a) rapid changes in the thermohaline circulation, b) ocean and ice processes related to climate, and mechanisms causing significant variability in the hydrography, circulation and ice cover and c) to maintain time series for early detection of climate change in the Northern seas.

For rapid and dramatic changes, i.e. essential changes in ocean circulation and ice-sheet on time scale 100 years or less, we have focused on two episodes, the Younger Dryas and Heinrich 4 about 13,000 and 40,000 years ago respectively. Efforts have been concentrated on constructing time slice maps based on various palaeoclimatic proxies from 38 sediment cores in the northern North Atlantic. The preliminary maps show low sea surface temperature (SST) for most of the area from percentage of $N$. pachyderma, but marked gradients with depleted values along continental margins and northeast of Iceland for $\delta^{18} \mathrm{O}$ N. pachyderma(s). During the Younger Dryas, strong brine formation took place, and major changes in deep ocean circulation occurred. At the end of the Younger Dryas SST increased by about $5^{\circ} \mathrm{C}$ within less than a decade, consistent with earlier ice core studies.

Observations in the Greenland Sea have shown deepwater ventilation in cold core anticyclonic eddies, with lifetimes of 1 year. These reach down to $2000 \mathrm{~m}$ depth and have a radius of a few kilometres.

Instrumental and historic observations, comprising multi-decadal to century-scale timeseries from around the Nordic Seas and adjacent areas,

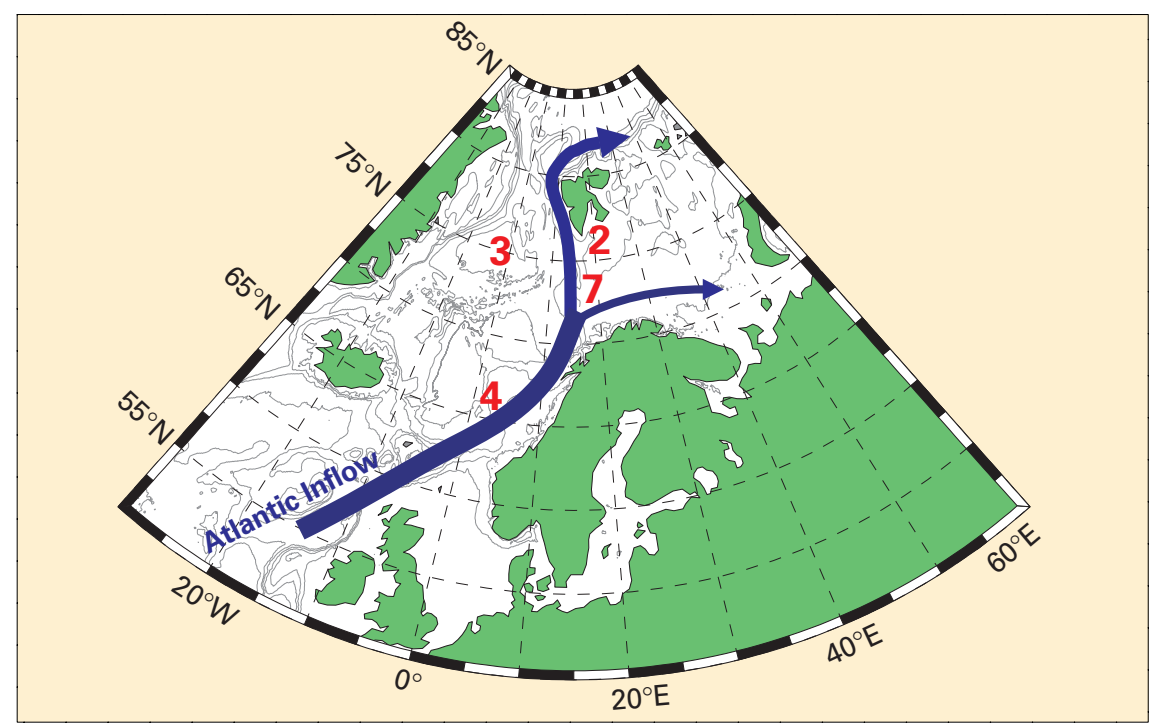

Fig. 1: Geographical working areas for specific studies in tasks 2, 3, 4, and 7 in the first phase of the project. Tasks 1, 5 and 6 will use data and model results from large parts of the entire area and are not shown on the map. Task 2 uses Storfjorden as a "laboratory" for process studies. Task 3 primarily covers the deep parts of the Nordic Seas. Task 4 deals with the front between Atlantic and Arctic Water. Task 7 addresses Atlantic inflow from the North Atlantic towards the Arctic as well as ice and freshwater flow through the Fram Strait.

have been collected as a coordinated dataset. Since the 1960s, sea level pressure from around the Icelandic Low region shows a delay of the consistent abrupt pressure rise in late February, which has contributed to the unusually positive winter NAO index values.

Paleo SST data from the Vøring Plateau show strong links to the $\mathrm{Ca}$ riaco Basin off Venezuela, indicating that northward movement of the intertropical convergence zone coincides with higher SST in the Nordic Seas. SST for the last 2000 years shows decadal-scale variability of $1-2^{\circ} \mathrm{C}$ in the Norwegian Atlantic Current and $3-4^{\circ} \mathrm{C}$ in the Irminger Current. A proxy record from Malangen, northern Norway shows a gradual warming of bottom water after $A D$ $1900\left(0.5^{\circ} \mathrm{C}\right)$.

An ensemble of multi-decadal to century-scale temperature and ice datasets in combination with global atmosphere-ocean climate modeling shows the patterns of variability in Arctic temperature and sea ice in the last two decades to be distinct from an early 20th-century warm period and indicates that recent changes are a response to greenhouse warming.

Monitoring has been concentrated on the inflow of Atlantic water into the arctic and the deepwater characteristics. In the south, the Atlantic Water flux is estimated to be $4.4 \mathrm{~Sv}$ (1 $\left.\mathrm{Sv}=10^{6} \mathrm{~m}^{3} \mathrm{~s}^{-1}\right)$ in the eastern branch and 3.4 Sv for the western branch. ADCP current meter observations in the Fugløya-Bear Island section show that during 2001 there has been a generally lower inflow to the Barents Seas. In the Fram Strait, monthly current velocity means averaged over two years show a net transport of 1.6 $\pm 1.7 \mathrm{~Sv}$ to the south. The transport maximum is found in spring and the minimum in summer. During the 1990s, the maximum temperature increased in the Fram Strait and between Svalbard and Norway. The Greenland Basin type deepwater has retreated southwards during the last 20 years in the Fram Strait, and is being replaced by Eurasian Basin type water. In the central Greenland Sea, the deepwater temperature is increasing.

NOClim has been active for almost two years and, depending on further funding, will continue for another four.

More information can be found at www.noclim.org 


\section{National PACE}

Mrhint thirur

IInIII I t

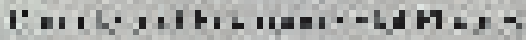

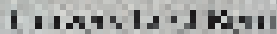

X-14. 19.

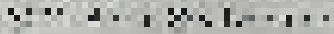

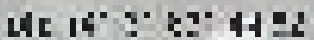

In $1 \div 1 \geqslant 1 \% 1 \% 4$

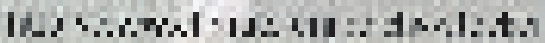

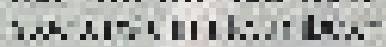

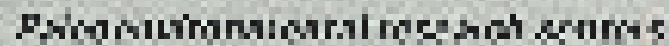

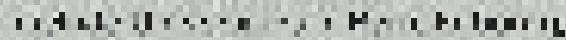

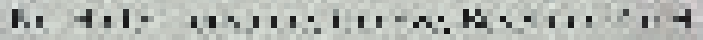

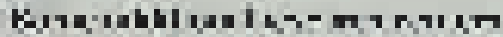

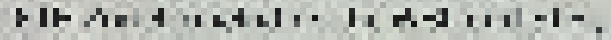

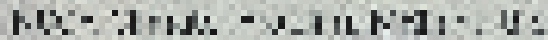

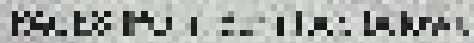

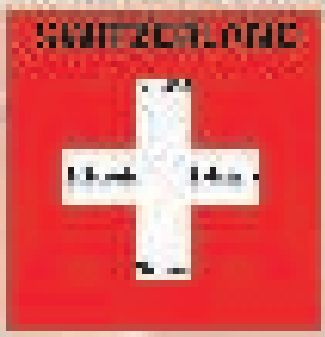

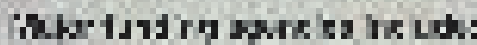

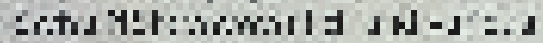

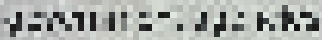

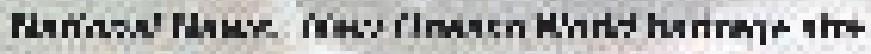

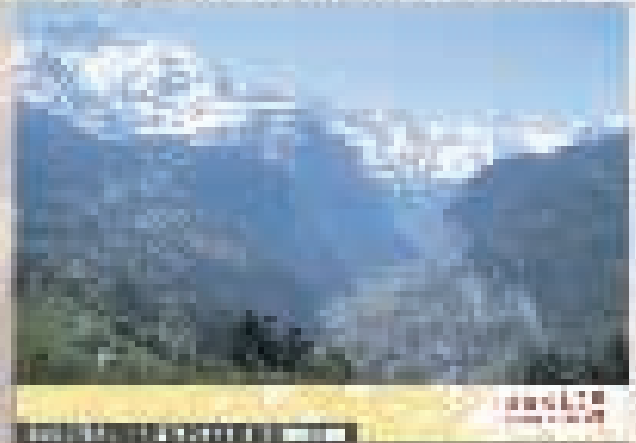

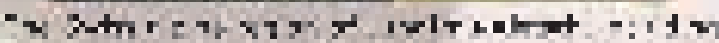

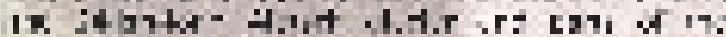

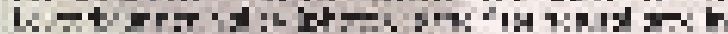

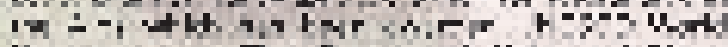

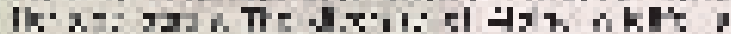

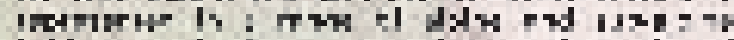

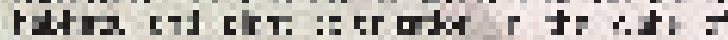

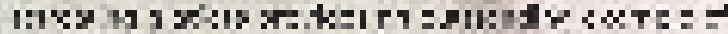

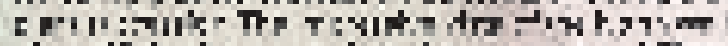

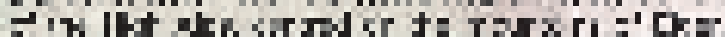

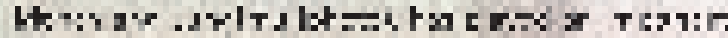

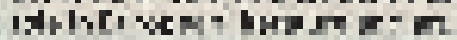

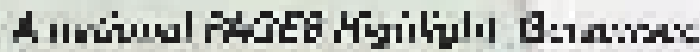

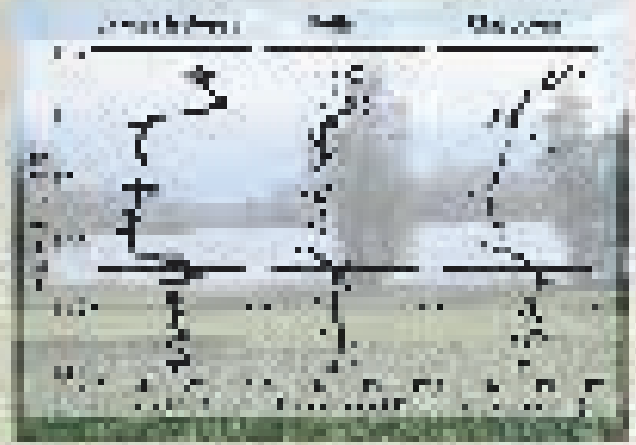

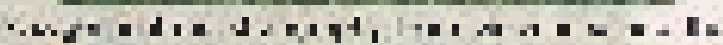

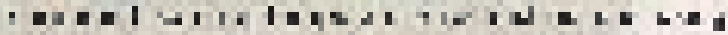

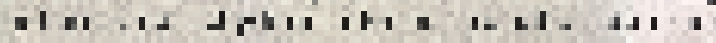

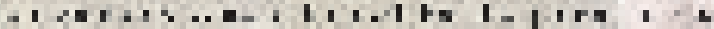

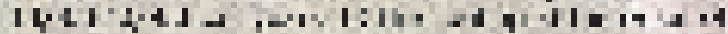

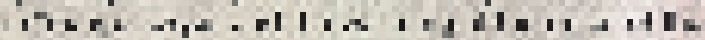

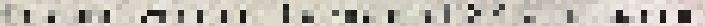

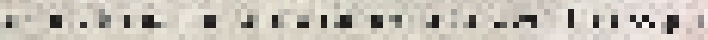

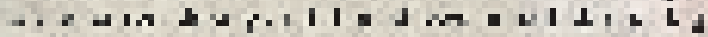

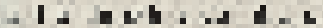

F. "

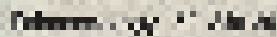

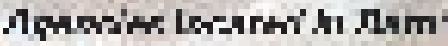

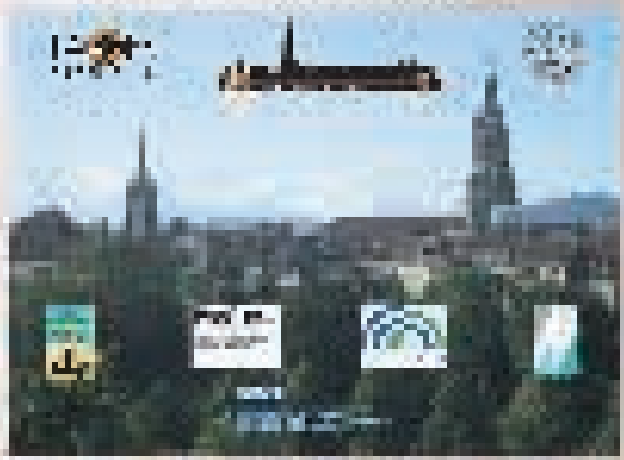

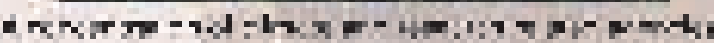

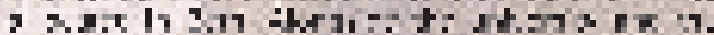

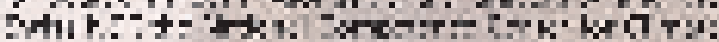

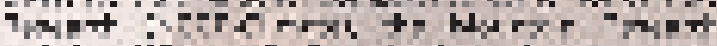

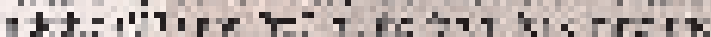

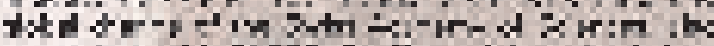

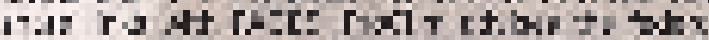

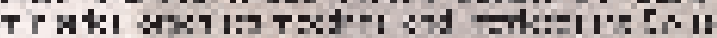

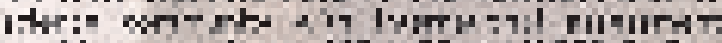

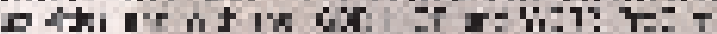

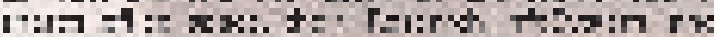

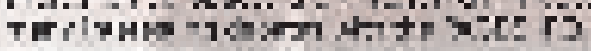

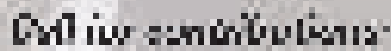

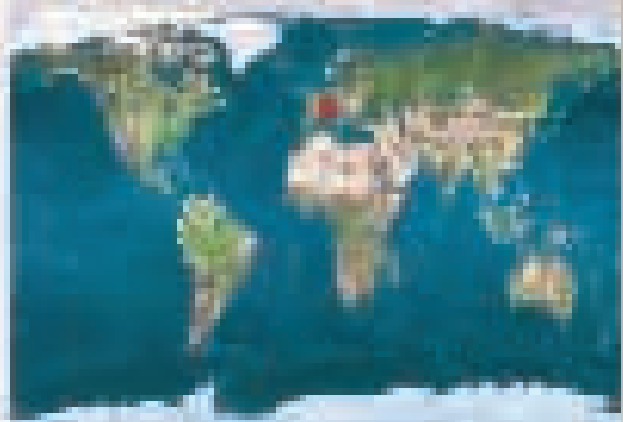

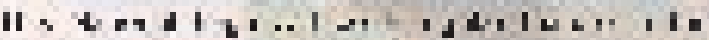

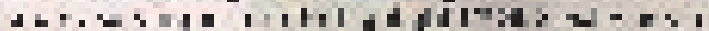

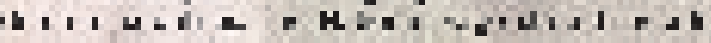

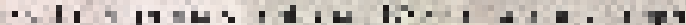

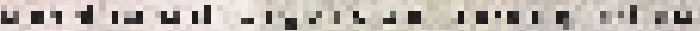

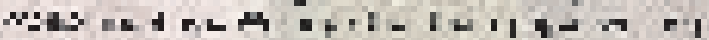

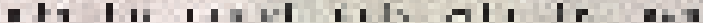

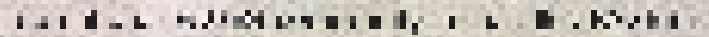

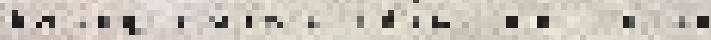

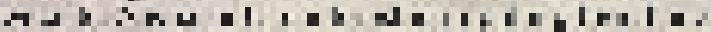

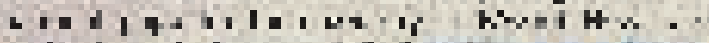

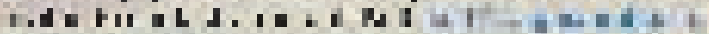

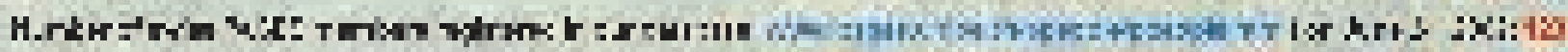




\title{
Extending Isotope in Precipitation Data Beyond Direct Measurements: The Perspective From Glacier Ice-Core Measurements in Switzerland
}

\author{
UlRich SChOTtereR $^{1}$ and Willibald STichleR ${ }^{2}$ \\ ${ }^{1}$ Climate and Environmental Physics and Department of Chemistry, University Bern, Switzerland; schotterer@climate.unibe.ch \\ 2GSF-Institute for Hydrology, Neuherberg, Germany; willibald.stichler@gsf.de
}

For paleoclimatic applications of stable isotope records two premises have to be fulfilled, namely, (1) that the isotope composition of the proxy material can be related to the water cycle of the past, and (2) that the relevant hydroclimatic parameters contributing to the record can be evaluated. Ice cores clearly play a central role within the goal of ISOMAP, because they potentially provide one of the most direct archives of paleoprecipitation, yet basic monitoring and process studies in situ are required to ensure that the transfer functions between the isotopic composition of the precipitation that is preserved and the conditions at the time of its formation are clearly elucidated.

Isotopes have been measured regularly in monthly composites of precipitation in Switzerland since 1970. The official Swiss network for isotopes in the hydrological cycle, operated by the Federal Office for Water and Geology, became operational in 1992. The network data cover the principal hydrometeorological regions of Switzerland at different altitudes, and therefore afford a unique opportunity to extend data records back in time via linking with high-resolution measurements from ice cores (or other archives).

Particularly well-resolved ice-core records have been obtained from the cold Fiescherhorn Plateau, situated in the Berner Oberland at an elevation of $3950 \mathrm{~m}$ (see Frontpage and upper panel, Fig. 1), which was drilled in both 1987 and 2000. The glacier is characterized by a notably high accumulation rate (1-2 $\mathrm{m}$ of water equivalent per year), potentially providing extremely fine temporal resolution. Isotopic determinations $\left(\delta^{18} \mathrm{O}, \delta^{2} \mathrm{H},{ }^{3} \mathrm{H}\right)$ were accompanied by measurement of a suite of relevant environmental tracers at close intervals, constituting up to 35 samples per year. As shown in Figure 1 (middle panel), systematic annual

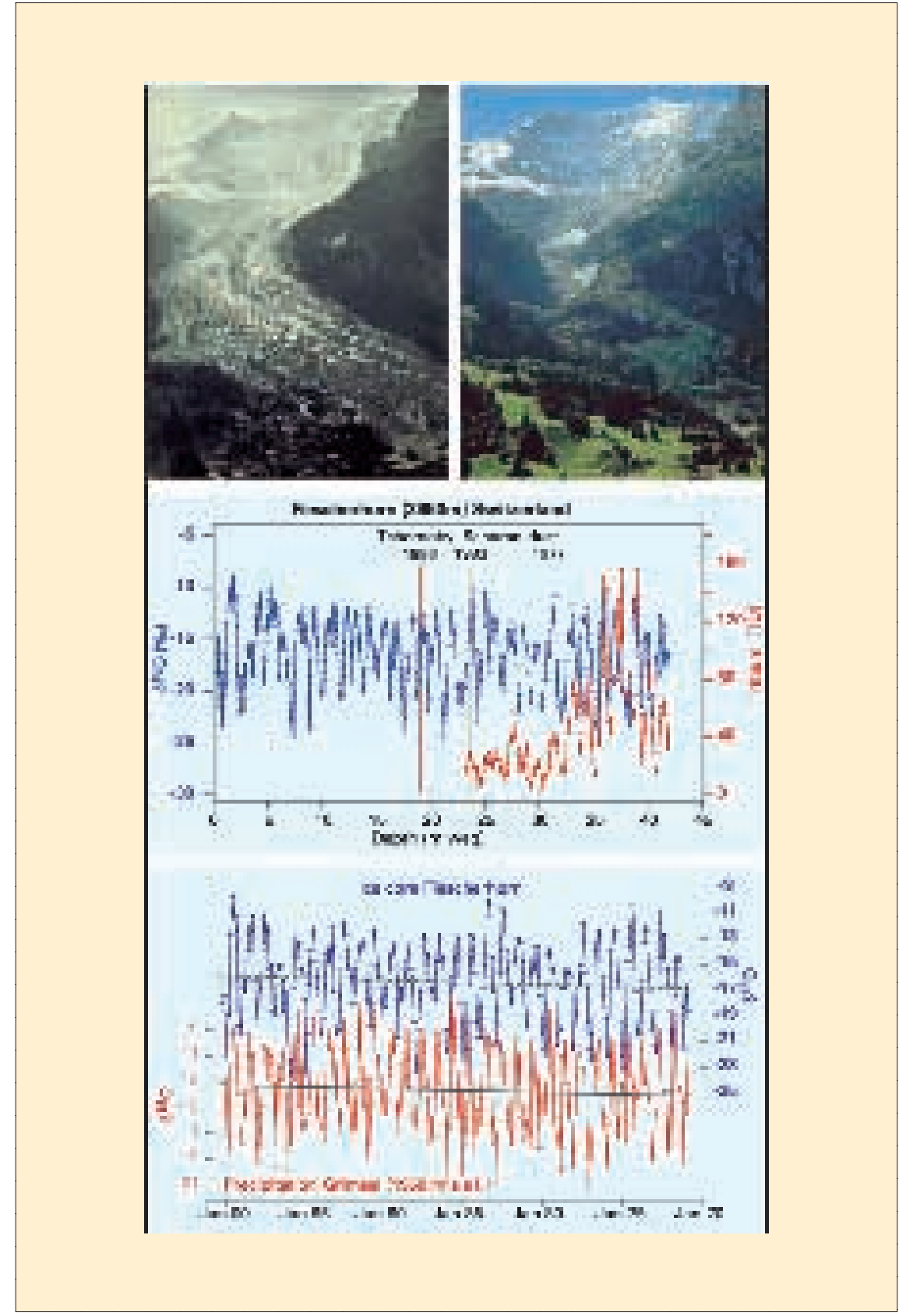

Fig. 1: Two views of the Lower Grindelwald Glacier, Fiescherhorn, from the same vantage point, revealing significant retreat between 1858 (left) and 1974 (right). The middle panel shows the stacked ice core $\delta^{18} \mathrm{O}$ record for 1970-2000 in terms of depth (metres water equivalent), in company with the ${ }^{3} \mathrm{H}$ record and key time markers. The lower panel illustrates the same $\delta^{18} \mathrm{O}$ record in terms of time, calibrated against the $\delta^{18} \mathrm{O}$ record of monthly composite precipitation from Grimsel. Although both records share the same strong annual cycle and longterm trend, remarkably weak correlation exists at finer scale.

cycles of variation in $\delta^{18} \mathrm{O}$ are clearly apparent for the entire Fiescherhorn record, anchored on some discrete time markers, suggesting that the series is continuous and complete. Given this unprecedented degree of resolution and the quality of ac- companying meteorological information, this data set should be ideally suited for rigorous evaluation of the hydrometeorological information archived in this alpine glacier.Yet this task is not straightforward, since the challenge of defin- 


\title{
Science Highlights
}

ing an absolute "ice-core calendar", to permit direct comparison with contemporaneous isotopic and meteorological data, still persists: Although the data measured in the ice core provide unmistakable evidence for the passage of time, where does a particular month (or season or year) actually begin and end? Thus, in spite of the unusually high resolution, the Fiescherhorn ice-core chronology may not be able to support evaluation of isotope-climate relations with the same level of confidence or at temporal scales equivalent to that possible using data from sampling of monthly composite precipitation.

Indeed, this limitation can be demonstrated by comparing the stacked Fiescherhorn $\delta^{18} \mathrm{O}$ record with the monthly composite precipitation $\delta^{18} \mathrm{O}$ record from Grimsel, a high-elevation station (1950 m) less than $25 \mathrm{~km}$ distant (lower panel, Fig. 1). Even extensive adjustment to achieve a best-fit with this monthly time-series yields only weak correlation, in spite of the visual impression imparted by the strong

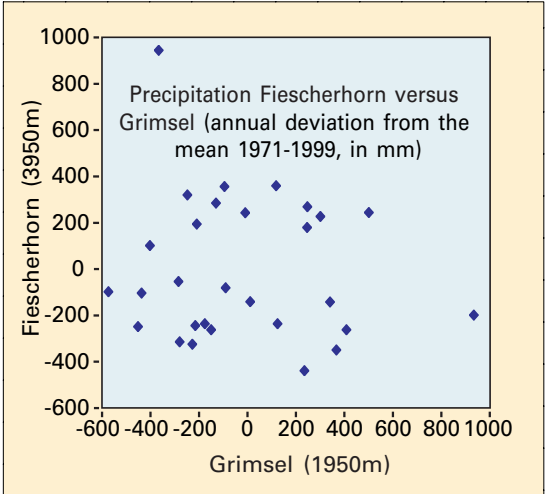

Fig. 2: Comparison of net annual accumulation at Fiescherhorn and precipitation amount at Grimsel. The lack of correspondence, consistent with the weak isotopic correlation evident in Fig. 1, underscores the need for critical evaluation of alpine ice core records.

annual cycling in both records and the similar longterm trends. Subsequent comparison with the North Atlantic Oscillation index (not shown), which generally correlates significantly with composite monthly European isotope records, also reveals weak correspondence. The most likely explanation to account for the apparent deficiency in the ability of this glacier to archive paleoprecipitation is revealed clearly by the plot shown in Figure 2, which shows that no cor- respondence exists between the net annual accumulation at Fiescherhorn and the amount of annual precipitation at Grimsel. This probably reflects at least in part the influence of drifting and other postdepositional processes that remove or redistribute snow, reminding us that alpine glaciers (and certainly to some extent polar ice sheets) are dynamic, open systems for precipitation, and that due caution is required in attempting to decipher their isotopic records.

\section{REFERENCES}

Schotterer, U., Schwarz, P. and Rajner, V., 1998: From pre-bomb levels to industrial times: A complete tritium record from an alpine ice core and its relevance for environmental studies. Proceedings, Isotope Techniques in the Study of Environmental Change, IAEA, Vienna, Vienna, April 1997, IAEASM-349, 581-590.

Schotterer, U., Stichler, W., Graf, W., Bürki, H.U., Gourcy, L., Ginot, P. and Huber, T., 2002: Stable isotopes in alpine ice cores: Do they record climate variability? Proceedings, International Conference on the Study of Environmental Change Using Isotope Techniques, Vienna, April 2001, IAEA-CN-80.

Stichler, W. and Schotterer, U., 2000: From accumulation to discharge: modification of stable isotopes during glacial and postglacial processes. Hydrological Processes 14: 1423-1438.

\section{Holocene Variability in the Indian Ocean Monsoon: A Stalagmite- Based, High-Resolution 0xygen Isotope Record from Southern Oman}

\author{
Dominik Fleitmann $^{1}$, Stephen J. Burns ${ }^{2}$, Manfred Mudelsee ${ }^{3}$, Ulrich NefF $^{4}$, Jan Kramers ${ }^{1}$, Augusto Mangini ${ }^{4}$ and Albert $_{\text {Matter }}{ }^{1}$ \\ 1 Institute of Geological Sciences, University of Bern, Switzerland; fleitman@geo.unibe.ch, kramers@geo.unibe.ch, albert.matter@geo.unibe.ch \\ 2 Department of Geosciences, Morrill Science Center, University of Massachusetts, USA; sburns@geo.umass.edu \\ 3 Institute of Meteorology, University of Leipzig, Germany; mudelsee@rz.uni-leipzig.de \\ ${ }^{4}$ Environmental Physics, Heidelberger Academy of Sciences, Germany; Augusto.Mangini@iup.uni-heidelberg.de
}

The Indian Ocean monsoon is one of the major weather systems on Earth, affecting the economies, agriculture and fisheries of one of the most densely populated areas of the world. To date, analyses of how and why the monsoon varies through time have mainly been restricted to studies of meteorological records, which extend back perhaps $150 \mathrm{yr}$, or to investigations of lacustrine and marine sediments, which have a low time-resolution (typically greater than 100 years) and large age uncertainties. However, one sensitive monitor of monsoon variation having considerably finer temporal resolution is the oxygen isotope composition of stalagmites, such as those from Qunf Cave (17 ${ }^{\circ} 10^{\prime} N, 54^{\circ} 18^{\prime} \mathrm{E}$; 650 m.a.s.I.) in

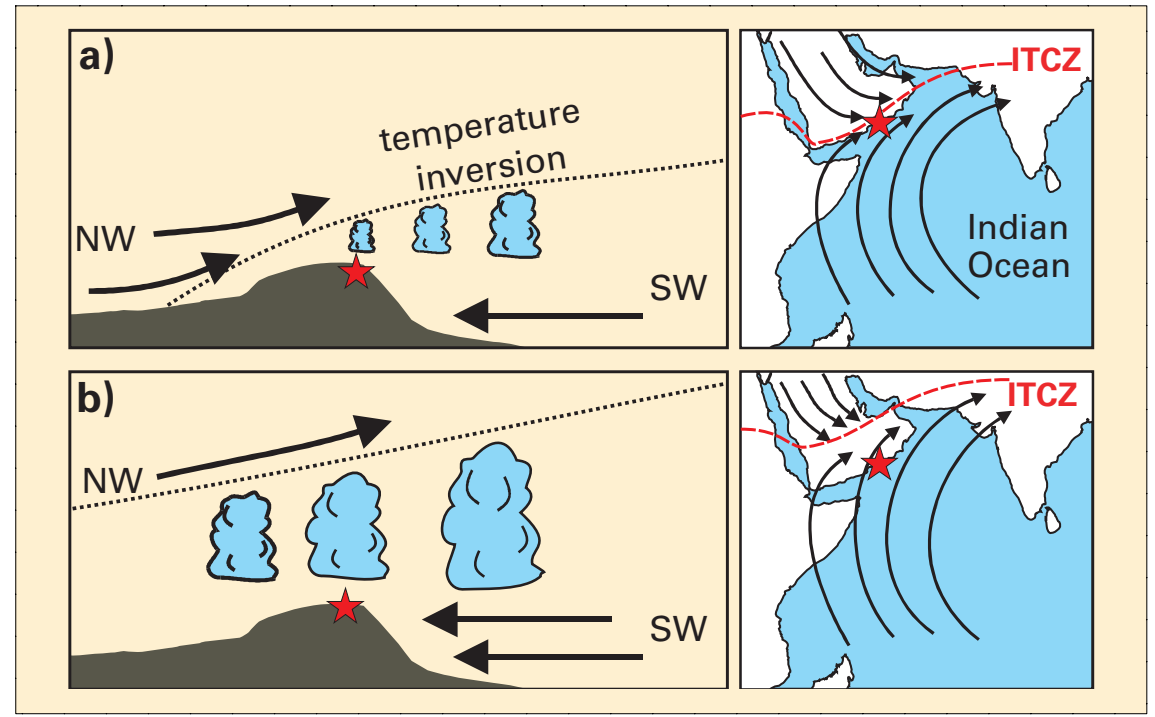

Fig. 1: a Modern summer circulation pattern over Southern Oman. The red star shows the location of Qunf Cave. The black dashed line shows the position of the temperature inversion and the red dashed line the location of the ITCZ. $\boldsymbol{b}$ Schematic figure of summer circulation pattern at around $7 \mathrm{kyr} B P$. 


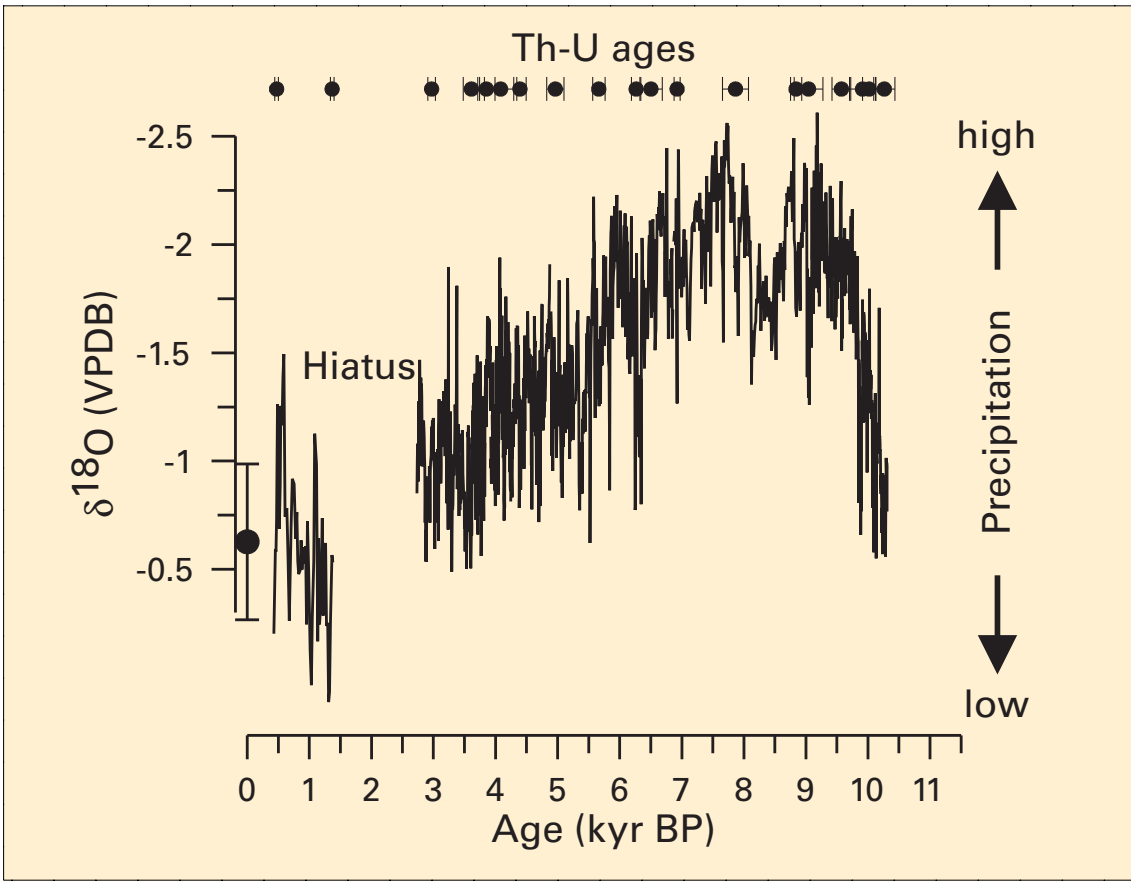

Fig. 2: Stalagmite Q5 oxygen isotope record from Southern Oman. Black dots above are U-Thages (Fleitmann et al., submitted). Black dot with vertical error bar shows the $\delta^{18} \mathrm{O}$ range of modern stalagmites (101 stable isotope measurements, 50 years).

southern Oman (Fig. 1a), which precipitate from drip water that accurately reflects the oxygen-isotope content of local monsoon rainfall (Fleitmann et al., 1999).

Presently, the area lies at the northern limit of the summer migration of the ITCZ and the associated Indian Ocean monsoon rainfall belt. Annual precipitation in this region is highly seasonal - more than $80 \%$ of total annual precipitation $\left(400-500 \mathrm{~mm} \mathrm{yr}^{-1}\right)$ falls during the summer monsoon months (July to September) when dense clouds and mists cover the region. The clouds are unable to rise higher than about $150 \mathrm{~m}$ because of a temperature inversion created by the convergence between hot dry northwesterly winds off the land and the low-level southwest monsoon winds off the ocean (Fig. 1a). As a result, monsoon precipitation occurs as fine drizzle, seldom exceeding more than $5 \mathrm{~mm} \mathrm{~d}^{-1}$, unlike the heavy rains normally associated with strong convective monsoonal rainfall.

Stalagmite 05 was deposited in two phases from 10.3 to $2.7 \mathrm{kyr}$ BP and from 1.4 to $0.5 \mathrm{kyr} \mathrm{BP}$ (the data are presented on the ${ }^{14} \mathrm{C}$ absolute age scale where "present" is defined as AD 1950). The oxygen isotope profile (Fig. 2) has an average time-resolution of $5 \mathrm{yr}$. When stalagmites are deposited in isotopic equilibrium (i.e., no evaporation), calcite $\delta^{18} \mathrm{O}$ values reflect either changes in the isotopic composition of precipitation or changes in mean annual air temperature within the cave. Previous work on stalagmites from northern and southern Oman have demonstrated that changes in calcite $\delta^{18} \mathrm{O}$ over time primarily reflect changes in the amount of precipitation (Burns et al., 2001; Neff et al., 2001). More negative $\delta^{18} \mathrm{O}$ values indicate greater monsoon precipitation, because $\delta^{18} 0$ of monsoon-type precipitation is commonly correlated inversely to the amount of precipitation (the socalled "amount effect", see Dansgaard, 1964).

The $\delta^{18}$ O-profile (Fig. 2) of stalagmite 05 shows three distinct features. First, a rapid increase in monsoon precipitation between 10.3 and $9.8 \mathrm{kyr} \mathrm{BP}$ is indicated by a sharp decrease in $\delta^{18} \mathrm{O}$ from - $0.8 \%$ 。 to $\sim-2 \%$. Second, an interval of generally high monsoon precipitation lasting from 9.8 to $5.5 \mathrm{kyr} \mathrm{BP}$ with $\delta^{18} \mathrm{O}$ values averaging $-2 \%$. Third, a long-term gradual decrease in monsoon precipitation starting at around $7 \mathrm{kyr} \mathrm{BP}$ is indicated by a slow shift in average $\delta^{18} \mathrm{O}$ from $-2.2 \%$ at $7 \mathrm{kyr} B P$ to $\sim-0.9 \%$ (slight- ly more negative than $\delta^{18} \mathrm{O}$ values of modern stalagmites) at $2.7 \mathrm{kyr}$ BP. Furthermore, the early to midHolocene period of generally high monsoon precipitation was apparently interrupted by three distinct intervals of reduced precipitation, occurring at around 9.2-9.1, 8.5-8.1 and 6.3-6.2 kyr BP.

What circulation pattern controlled the amount of monsoon precipitation in southern Oman over the course of the Holocene? The Q5 $\delta^{18} \mathrm{O}$ record is consistent with the scenario depicted in Figure $1 b$, showing postulated northward displacement of the ITCZ around $7 \mathrm{kyr}$ BP. Such a shift of the ITCZ into the Arabian Peninsula, as inferred from lake sediments (McClure, 1976) and stalagmites (Burns et al., 2001; Neff et al., 2001), would lift the height of the temperature inversion, leading to stronger convective cloud development and higher monsoonal rainfall over southern Oman. Moreover, the fine structure in the $\mathrm{Q} 5$ $\delta^{18} 0$ record suggests that characteristic variations also occur at much higher frequencies, affording the opportunity to gain insight into monsoon circulation dynamics and variability under a range of boundary conditions, and at time-scales relevant to humans.

\section{References}

Burns, S.J., Fleitmann, D., Matter, A., Neff, U. and Mangini, A., 2001: Speleothem evidence from Oman for continental pluvial events during interglacial periods. Geology 29: 623-626.

Dansgaard, W., 1964. Stable isotopes in precipitation. Tellus 16: 436-468.

Fleitmann, D., Burns, S.J. and Matter, A., 1999: Stable isotope study of the active water-carbonate system in caves in Oman: a test of applicability to paleoclimate studies. EOS 80: 523.

Fleitmann, D., Burns, S.J., Mudelsee, M., Neff, U., Kramers, J., Mangini, A. and Matter, A., submitted: Variable Holocene forcing of the Indian Ocean monsoon recorded in stalagmites from southern Oman. Nature.

Neff, U., Burns, S.J., Mangini, A, Mudelsee, M. Fleitmann, D. and Matter, A., 2001: Strong coherence between solar variability and the monsoon in Oman between 9 and 6 kyr ago. Nature $\mathbf{4 1 1}$ : 290-293.

McClure, H.A., 1976: Radiocarbon chronology of late Quaternary lakes in the Arabian desert. Nature 263: 755-756. 


\title{
Isotopic Records of Past Hydroclimatic Change in the Red River Basin, Southern Manitoba, Canada
}

\author{
William M. Buhay ${ }^{1}$, Danny Blair ${ }^{1}$, Erik Nielsen ${ }^{2}$, Scott St. George ${ }^{3}$ and Greg Brooks 4 \\ ${ }^{1}$ Department of Geography, University of Winnipeg, Winnipeg MB, Canada, R3B 2E9; b.buhay@uwinnipeg.ca; d.blair@uwinnipeg.ca \\ ${ }^{2}$ Manitoba Geological Survey, 360-1395 Ellice Avenue, Winnipeg MB, Canada, R3G 3P2; Enielsen@gov.mb.ca \\ ${ }^{3}$ Geological Survey of Canada, 360-1395 Ellice Avenue, Winnipeg MB, Canada, R3G 3P2; sstgeorg@NRCan.gc.ca \\ ${ }^{4}$ Geological Survey of Canada, 601 Booth St., Ottawa ON, Canada, K1A 0E8; gbrooks@NRCan.gc.ca
}

Experience during the $20^{\text {th }}$ century has shown that southern Manitoba is prone to intense hydrological changes, including multiyear droughts and extreme flooding. Models project some portions of the Canadian prairies to experience a 40 percent decrease in average soil moisture by the second half of the $21^{\text {st }}$ century, with an attendant increase in the frequency and magnitude of future prairie droughts. A shift to more arid conditions would have considerable socio-economic impacts and lead to lower crop yields, increased demand for groundwater and reduced hydroelectric power production. However, these predictions are limited by the length and spatial distribution of modern instrumental records. As instrumental records

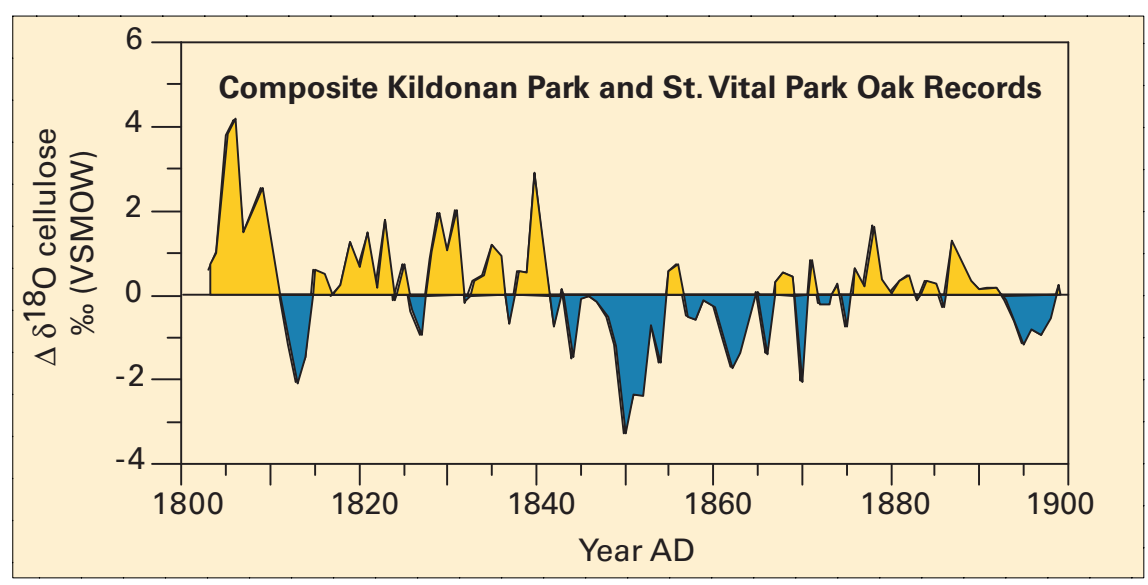

Fig. 1: Amalgamated $\delta^{18} \mathrm{O}$ values for three oak trees from the Red River basin (Kildonan 1, Kildonan 2, St. Vital 1) for the $19^{\text {th }}$ century. Negative departures from the mean (blue) correspond to flood and high water stages of the Red River (historically: 1811, 1826, 1849-52, 1861 and 1896). Positive departures from the mean (yellow) correspond to drought and dry periods (historically: 1803-1805; 1816-1820, and 1840).

in Manitoba are relatively short and sparse, conditions observed during the $20^{\text {th }}$ century may not represent true "worst-case" scenarios. Pro-

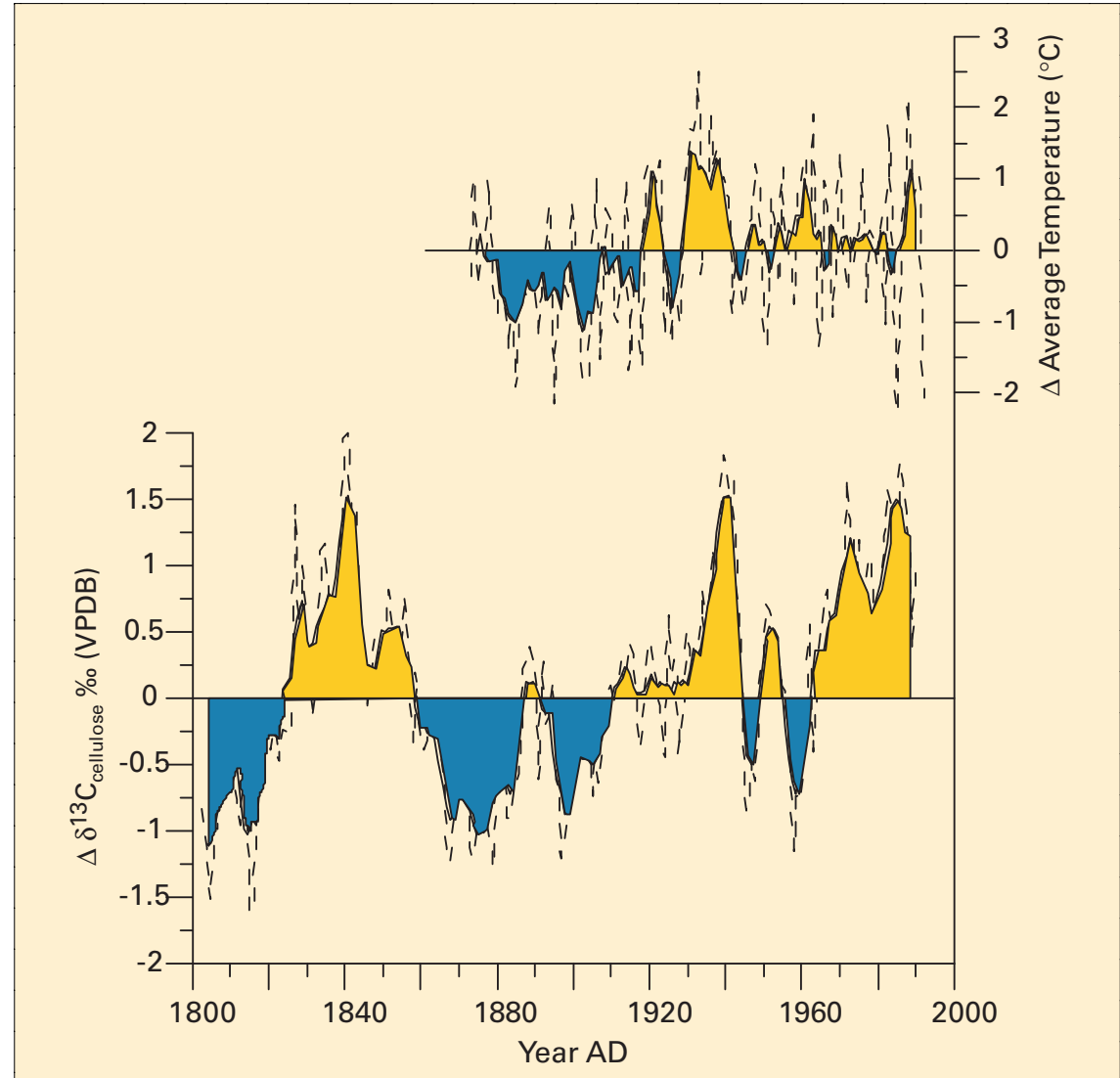

Fig. 2: Top: Average growing season temperature (departures from average) (June to September) for the Red River basin from 1874 to 1992). Bottom: $\delta^{13} \mathrm{C}$ values for three oak trees from the Red River basin (Kildonan 1, Kildonan 2, St. Vital 1) for the $19^{\text {th }}$ and $20^{\text {th }}$ centuries. jections regarding the magnitude of future climatic change and the frequency of extreme climate events can be enhanced by the extension of regional climate history prior to instrumental and written historical records.

Isotope variations in tree-ring cellulose offer great potential for yielding good proxy flood records because of the wide geographical distribution of suitable sites, fine temporal resolution, and length of available records, as well as their identified environmental sensitivity. Isotope dendroclimatology has proven to provide accurate estimates of atmospheric climate parameters that cannot be provided by conventional analysis. This approach to paleoclimatic reconstruction is based on deconvolution of the independent isotopic signatures of oxygen and carbon preserved in the cellulose fraction of plant tissues. The isotopic ratios depend on the initial composition of water taken up by the tree (which often correlates with local air temperature) and the degree of subsequent isotopic enrichment of the plant water due to evapotranspirative vapour loss (which is dependent on the atmospheric moisture regime). Isoto- 
pic fractionations occurring during evapotranspiration and cellulose synthesis can be modelled semiempirically to permit quantitative derivation of paleo-isotope values for local meteoric water (and hence paleotemperature) and paleohumidity.

This preliminary study utilizes stable isotope techniques to examine recent climate change in the Red River basin of southern Manitoba, Canada. At present, the regional tree-ring record extends from $A D$ 1999 to AD 1286. Isotopic data has been extracted from three trees from Winnipeg parks to generate an annual record of fluctuations in oxygen and carbon isotopes from 1802 to 1990 (see Figs. 1 and 2 below). These preliminary results suggest that the isotopic variations in the trees are closely linked to past variations in regional hydroclimate and growing season temperature.
Amalgamated oxygen and carbon isotopic values for the three tress (2 oak trees from Kildonan Park and one from St. Vital Park) are presented to illustrate departures from mean oxygen (Fig. 1) and carbon (Fig. 2) values.

In Figure1, negative oxygen-18 anomalies (indicating significantly depleted oxygen isotope values) are centred on the historical 1811, 1826, 1852 and 1861, 1896. Positive oxygen-18 anomalies correspond nicely with historical droughts (1803-1805; 1816-1820) and excessively dry periods (1840).

When compared with Winnipeg instrumental records, preliminary delta $\delta^{13} \mathrm{C}$ cellulose values portrayed as departures from a mean show a fairly positive relationship with recorded growing season temperature variations (average monthly daytime temperatures from June to September). Particularly noteworthy in Figure 2 is a period between 1874 and 1935 characterized by increasing growing season temperatures, which is positively mimicked by delta $\delta^{13} \mathrm{C}$ cellulose that change from below to above average values. Additionally, Figure 2 hints towards a particularly warm period during the middle of the $19^{\text {th }}$ century proceeded by a cold period that mimics the historical late $19^{\text {th }}$ century cold period. The initial results of this research indicate that oak cellulose oxygen isotope departures from a mean do provide historically reasonable chronological signatures of floods and droughts in the Red River basin. Additionally, carbon isotope results provide qualitative estimates of growing season temperature variations and therefore a climate framework in which to place these flood and drought anomalies.

\section{A New Conceptual Model for Predicting Isotopic Enrichment of Lakes in Seasonal Climates}

JoHn J. Gibson

Department of Earth Sciences, University of Waterloo, Waterloo ON, Canada, N2L 3 G1 (Present address: International Atomic Energy Agency, Wagramerstrasse 5, P.O. Box. 100, Vienna, AUSTRIA) J.J.Gibson@iaea.org

Steady-state isotope balance models have often been applied to estimate long-term average water balance conditions for lakes (Dinçer, 1968; Gat, 1995). Such studies have commonly employed values for the kinetic isotope fractionations for oxygen and hydrogen determined from wind tunnel experiments (e.g. Vogt, 1976; see also Gonfiantini 1986) and have assumed isotopic equilibrium between atmospheric moisture and local mean annual precipitation (Rozanski et al., 2001; Gibson et al., 1993). In climates with a pronounced seasonality in evaporation rates, especially in environments where ice cover is present, such models have frequently predicted evaporative enrichment slopes that differ from observations (commonly lower than observed), and have therefore resulted in poor agreement between oxygen-18 and deuterium estimates, or have required use (or fitting) of kinetic frac- tionation factors that are not in agreement with experimental results (Zuber, 1983; Gibson et al., 1993).

A program of field investigations conducted at a variety of sites in northern Canada over the past decade has focused on development and application of quantitative isotope mass balance methods for water resources assessment in seasonal climates (see Gibson et al., 1994). These studies have included detailed comparisons of weekly to monthly evaporation in small, well-instrumented lakes using nonsteady isotope balance methods (Gibson et al., 1996a,b, 1998; Gibson 2002), regional comparisons of long-term water balance in boreal and arctic lakes (Gibson 2001; Gibson et al., 2002; Gibson and Edwards 2002), and application of evaporation pans and cryogenic vapour sampling to characterize isotopic composition of atmospheric moisture near the ground (Gibson et al., 1999). Overall, these studies have shown that application of isotope mass balance using pan-derived atmospheric moisture and laboratory values for kinetic exchange parameters yields consistent results for short time periods as compared to conventional water balance where evaporation is determined using Bowen ratio and aerodynamic profiling methods. Local and regional sampling surveys have also revealed a pronounced latitudinal steepening of the slope of local evaporation lines from about 5 to 7 in $\delta^{2} \mathrm{H}-\delta^{18} \mathrm{O}$ space over the latitude range of 50 to $71^{\circ} \mathrm{N}$.

A recent sensitivity analysis was conducted to investigate possible seasonality effects on the slope of the local evaporation lines that would explain the steeper slopes at higher latitudes, and the general lack of agreement between predicted evaporation slopes using 


\section{Science Highlights}

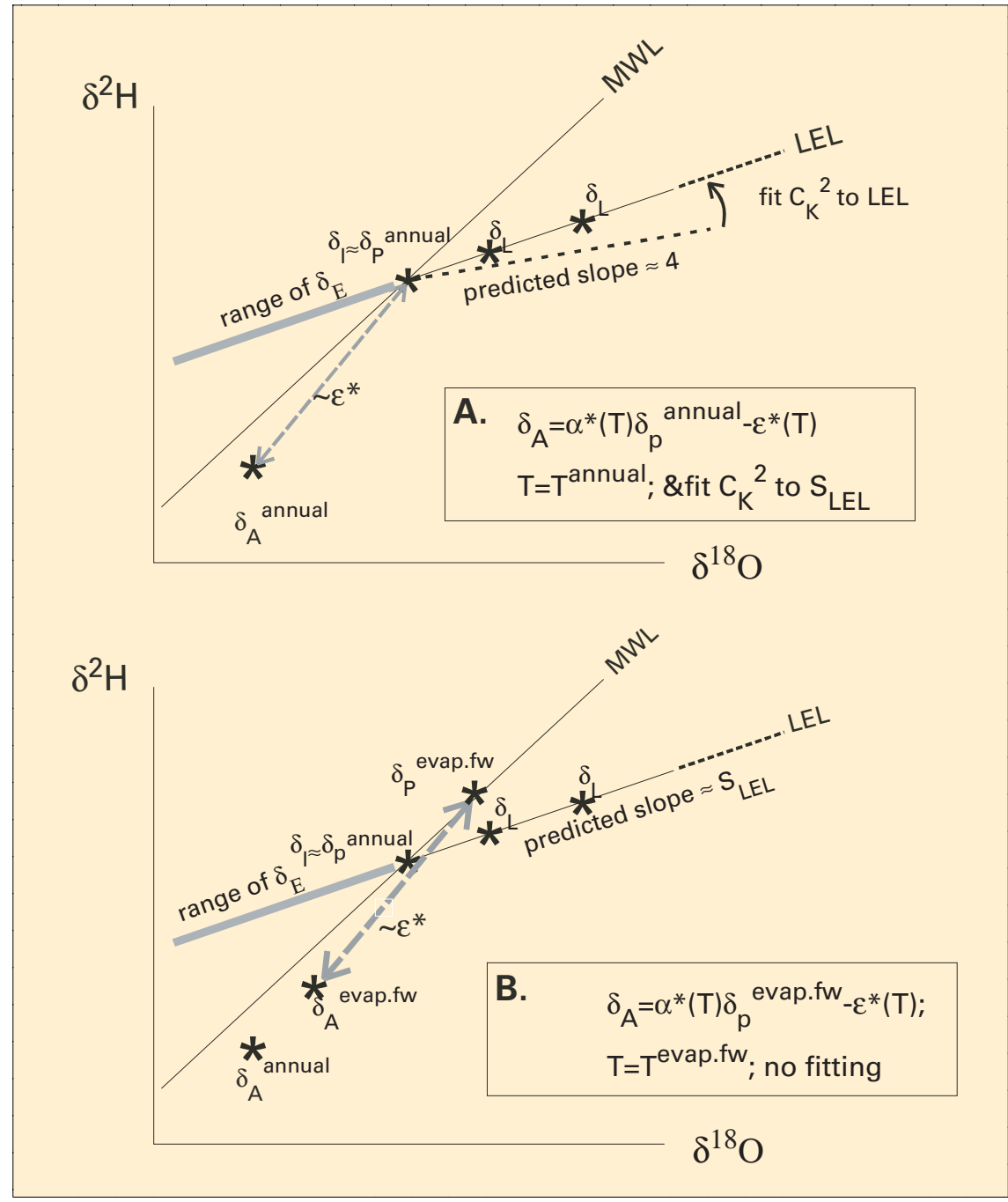

Fig. 1: Conceptual models showing the isotopic composition of major water balance components relative to the meteoric water line (MWL) and local evaporation line (LEL) in $\delta^{2} \mathrm{H}-\delta^{18} \mathrm{O}$ space: (a) original model assuming isotopic equilibrium between atmospheric moisture and precipitation (e.g. Gibson et al., 1993). Predicted slopes fall close to 4 and require fitting of the isotope exchange parameters to obtain good agreement between tracers; (b) refined model assuming equilibrium between flux-weighted precipitation and atmospheric moisture. Predicted slopes are close to the observed $L E L$ and do not require fitting of exchange parameters. $\delta_{P}$ is precipitation, $\delta_{A}$ is atmospheric moisture, $\delta_{E}$ is evaporating moisture, and $\delta_{\text {, are various }}$ lakewaters. $C_{K}{ }^{2}$ is the kinetic fractionation constant for deuterium, $\alpha^{*}(T)$ and $\varepsilon^{*}(T)$ are the respective equilibrium fractionation and separation factors for each isotope species, and $T$ is ambient temperature. Superscript "annual" and "evap. fw" denote mean annual and evaporation flux-weighted values.

the previously applied models. The analysis began by fitting atmospheric moisture $\left(\delta_{A}\right)$ so that predicted values of lake water $\left(\delta_{\mathrm{L}}\right)$ were constrained to fall on the local evaporation line. Notably, the resulting values of $\delta_{A}$ were also found to be very close to the values expected if weighted according to the evaporation flux, i.e., when $\delta_{A}$ is assumed to be in equilibrium with $\delta_{\mathrm{p}}$ but systematically filtered to account for the seasonality of the evaporation flux. Because the local evaporation line is a product of long-term evaporation from multiple lakes with differential throughflow, use of flux-weighted parameters is more realistic than use ters, as verified in the shorter-term field experiments. Lower slopes predicted by the original conceptual model are evidently due to improper (or lack of) weighting for the $\delta_{A}-\delta_{P}$ separation, which does not account for the absence of evaporation and isotope exchange during periods of ice-cover or for seasonal variability. An interesting point of particular relevance to paleoclimate studies is that temporal changes in seasonality may have altered the slope of the local evaporation in the past. Application of dual oxygen-18 and deuterium tracers to lake sediment archives may therefore be able to trace changes in slope of the local evaporation line, perhaps as a basis for examining changing seasonality. For modern water balance applications, the use of non-weighted atmospheric moisture values and standard exchange parameters can result in substantial errors in computed long-term values for evaporation-to-inflow ratios, particularly for strongly seasonal climates where errors may be as high as $50 \%$ for lakes having low throughflow and high evaporation. Another important implication is that the slopes of local evaporation lines should vary globally, with lower values at low latitudes and higher values at high latitudes and altitudes, which may be tested by spatial surveys of stable isotopes in surface waters.

\section{REFERENCES}

Dinçer, T., 1968: The use of oxygen-18 and deuterium concentrations in the water balance of lakes. Water Resources Research 4: 1289-1305.

Gat, J.R., 1995: Stable Isotopes of Fresh and Saline Lakes. In Physics and Chemistry of Lakes. Edited by A. Lerman, D. Imboden and J.Gat. Springer-Verlag, Berlin, 139-165

Gibson, J.J., 2002: Short-term evaporation and water budget comparisons in shallow arctic lakes using non-steady isotope mass balance Journal of Hydrology 264: 247-266.

Gibson, J.J. and Edwards, T.W.D., 2002: Regional surface water balance and evaporation-transpiration partitioning from a stable isotope survey of lakes in northern Canada. Global Biogeochemical Cycles 16: 25-38.

Gibson, J.J. Prepas, E.E. and McEachern, P., 2002: Quantitative comparison of lake throughflow, residency, and catchment runoff using stable isotopes: modelling and results from a survey of boreal lakes. Journal of Hydrology 262: 128-144.

For full references please consult:

www.pages-igbp.org/products/newsletters/ref2002_2.html 


\section{Modelling the Water Isotope Signal in the Quaternary}

\section{GeoRg HoffmanN}

Laboratoire des Sciences du Climat et de I'Environnement, DSM, Orme des Merisiers, Bâtiment 703, C.E. Saclay, 91191 Gif-sur-Yvette, FRANCE; hoffmann@Isce.saclay.cea.fr

Water isotopic signals from paleo archives represent multiparameterdependent climate records. Past changes in various quantities and processes may have affected the isotopic compositions of atmospheric moisture and precipitation. Even a detailed regional calibration study striving to understand all factors controlling the water isotopes on a seasonal to inter-annual basis cannot take into account the entire variety of possible changes in the past, ranging from circulation changes and corresponding changes in the distribution of source regions to changes of the local hydrological cycle (e.g., lakes, vegetation type and coverage), variations in the seasonality of the precipitation, etc.

General Circulation Models (GCMs) with an embedded isotope module allowing the prognostic computation of the water isotopes provide an effective means of testing the influence of a certain number of these different factors (Joussaume et al., 1984; Jouzel et al., 1987; Hoffmann et al., 1998; Werner et al., 2000). In an ongoing study, for example, a set of numerical simulations has been performed with

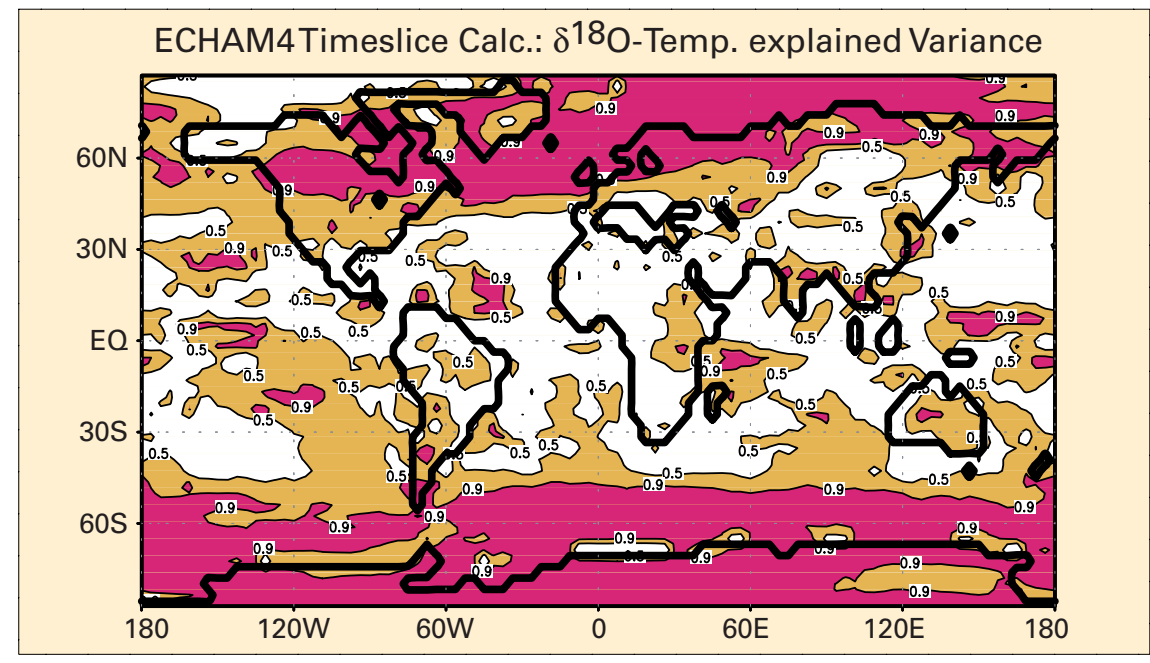

Fig. 1: Temporal correlation $(=r)$ between the isotope and temperature anomalies calculated for each point of the ECHAM4 grid for the Holocene time-slice calculations. As expected, the explained variance $\left(=r^{2}\right)$ of the isotope signal is characterised by a strong contrast between high and low latitudes.

tions traditionally originates from their role as a proxy for local temperatures, particularly at high latitudes. Therefore the first question the present study addresses is to what extent the regional $\delta^{18} \mathrm{O}$ or $\delta D$ signal is controlled by local temperature variations. Figure 1 shows the explained variance $\left(r^{2}\right.$ in a simple correlation approach) computed for the simulated water isotope signal and the corresponding temperatures. As expected, there is a distinct high- versus low-

Table 1: Boundary conditions for the six paleosimulations used in this study

\begin{tabular}{|llclll|}
\hline Time Slice & $\mathbf{C O}_{\mathbf{2}}$ & Insolation & SST & Sea Level & $\delta_{\text {Ocean }}$ \\
\hline $6 \mathrm{kyr} \mathrm{BP}$ & $280 \mathrm{ppm}$ & $6 \mathrm{kyr} \mathrm{BP}$ & Modern & Control & $0 \%$ \\
$11 \mathrm{kyr} \mathrm{BP}$ & $280 \mathrm{ppm}$ & $11 \mathrm{kyr} \mathrm{BP}$ & Interpol. CLIMAP & -30 Meters & $+0.4 \%$ \\
$14 \mathrm{kyr} \mathrm{BP}$ & $240 \mathrm{ppm}$ & $14 \mathrm{kyr} \mathrm{BP}$ & Interpol. CLIMAP & -60 Meters & $+0.8 \%$ \\
$16 \mathrm{kyr} \mathrm{BP}$ & $220 \mathrm{ppm}$ & $16 \mathrm{kyr} \mathrm{BP}$ & Interpol. CLIMAP & -87 Meters & $+1.2 \%$ \\
$21 \mathrm{kyr} \mathrm{BP}$ & $200 \mathrm{ppm}$ & $21 \mathrm{kyr} \mathrm{BP}$ & CLIMAP & -106 Meters & $+1.5 \%$ \\
$175 \mathrm{kyr} \mathrm{BP}$ & $200 \mathrm{ppm}$ & $175 \mathrm{kyr} \mathrm{BP}$ & CLIMAP & -106 Meters & $+1.5 \%$ \\
\hline
\end{tabular}

the ECHAM4 climate model of the Max-Planck Institut für Meteorologie, Hamburg, aiming to realistically reproduce six paleo time-slices of global climate 6 kyr BP, 11 kyr BP, 14 kyr BP, 16 kyr BP, 21 kyr BP, 175 kyr BP), plus "modern" and "preindustrial". Boundary conditions for the paleo time-slice calculations are listed in Table 1.

Though various factors control the isotopic composition of precipitation, the importance of the water isotopes in paleoclimate investiga- latitude pattern. In high northern or southern latitudes the water isotope signal is largely controlled by corresponding local temperature variation, in many areas more than $90 \%$. In contrast, at low latitudes (approximately $<45^{\circ} \mathrm{N}$ and S) the simulated isotope pattern is generally more strongly affected by precipitation intensity and circulation changes (though noting that temperature sensitivity does occur in some low-latitude locations because of convective precipitation triggered by temperature changes).

A key factor potentially biasing the interpretation of the water isotopes as a paleothermometer, even at high latitudes, is the seasonality of precipitation. Any change in the seasonal distribution of precipitation naturally shifts the annual mean water isotopic signal versus the corresponding seasons. The common assumption that the local spatial isotope-temperature gradient is a valid approximation of the temporal gradient (modern analogue approach) crucially depends on unchanged and approximately equally distributed seasonality. Figure 2 demonstrates the importance of this feature, focussing on the simulated seasonality of temperature, precipitation and water isotopes over central Greenland. In this region the simulated spatial $\delta^{18} \mathrm{O}-\mathrm{MAT}$ gradient under modern conditions is of the order $0.5 \% /{ }^{\circ} \mathrm{C}$, slightly lower than that observed. Whereas temperature and water isotopes are characterized by a strong but essentially unchanged seasonal cycle throughout the entire period, precipitation amount and seasonality are dramatically different under glacial and non-glacial conditions. Under non-glacial climate conditions, precipitation is 


\section{Science Highlights}

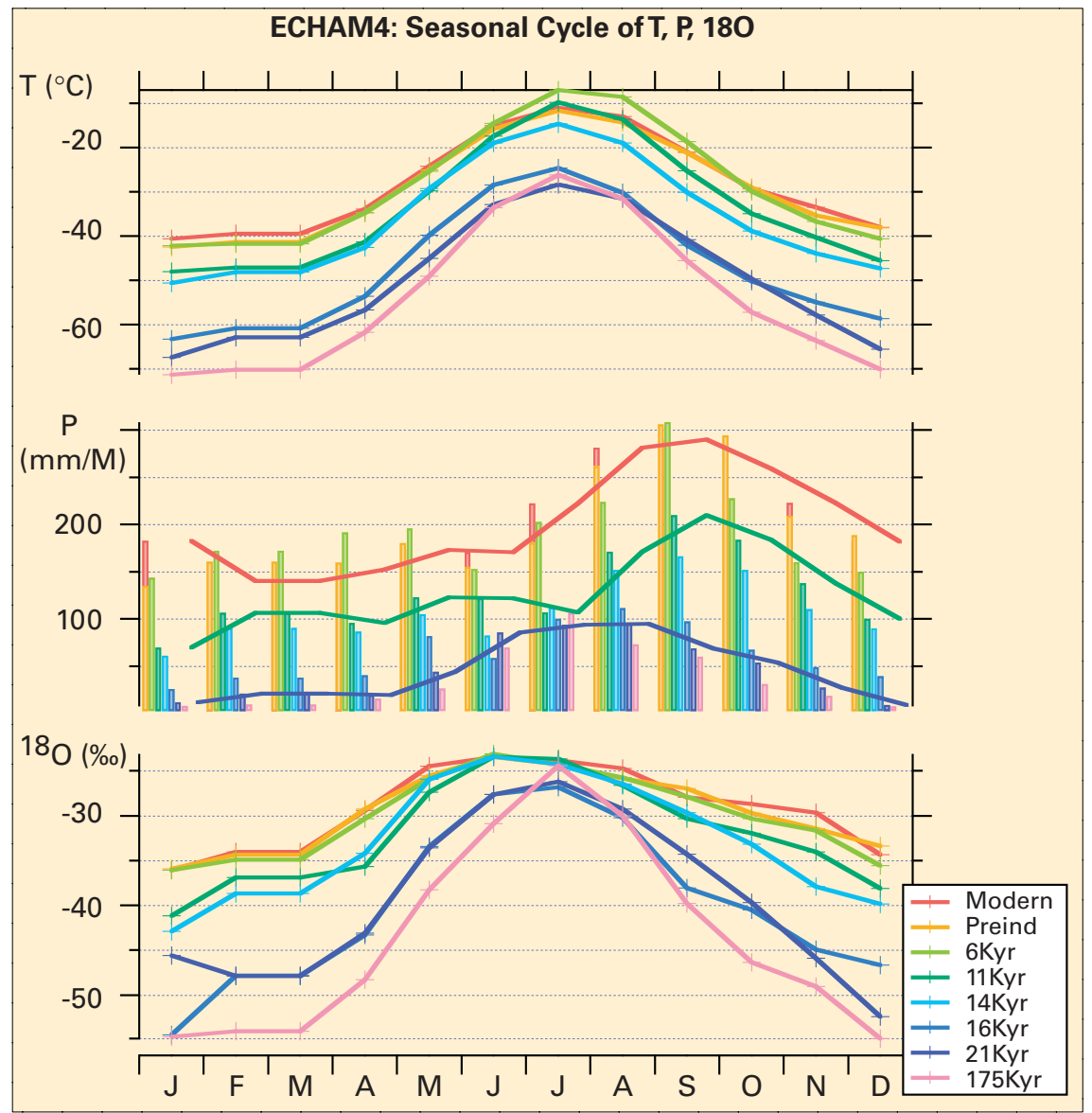

Fig. 2: Simulated (ECHAM4) seasonality of temperature, precipitation and $\delta^{18} \mathrm{O}$ over Central Greenland. Between $11 \mathrm{kyr} B P$ and $14 \mathrm{kyr} B P$ there is a pronounced reduction of winter precipitation, which is responsible for the strong bias of the isotope paleothermometer to warmer summer temperatures during near-and full-glacial conditions.

fairly equally distributed over the year, with a slight maximum in early autumn. A contrasting situation exists under near- or full-glacial conditions, marked by reduced precipitation overall, and most particularly during winter, thus strong- ly biasing the water isotope signal towards that of the summer. This mechanism explains about $70 \%$ of the difference between the simulated spatial and temporal isotopetemperature gradients - the latter being unreasonably low (in the or- der of $0.2 \% /{ }^{\circ} \mathrm{C}$ ) in the absence of correction for seasonality, which increases the gradient to about $0.4 \% \circ /{ }^{\circ} \mathrm{C}$. This provides a graphic example of the utility of isotopicGCMs as "thinking tools", since this profound shift in the temporal isotope-temperature relation can be related directly to the extreme southward shift of the winter polar front under glacial conditions and the concomitant suppression of meridional moisture transport to central Greenland, thus offering a clear mechanistic explanation for the apparent failure of the isotope paleothermometer across the glacial-interglacial transition (e.g., see Cuffey et al., 1995; Dahl-Jensen et al., 1998; Severinghaus et al., 1998; Lang et al., 1999).

\section{REFERENCES}

Cuffey, K.M., Clow, G.D., Alley, R.B., Stuiver, M., Washington, E.D. and Saltus, R.W., 1995: Large Arctic temperature change at the Glacial-Holocene transition. Science 270: 455-458.

Dahl-Jensen, D., Mosegaard, K., Gundestrup, N. Clow, G.D., Johnsen, S.J., Hansen, A.W. and Balling, N., 1998: Past temperatures directly from Greenland Ice Sheet. Science 282: 271-281.

Hoffmann, G., Werner, M. and Heimann, M., 1998: The water isotope module of the ECHAM atmospheric general circulation model - A study on time scales from days to several years, Journal of Geophysical Research 103: 16,871-16,896.

Joussaume, J., Sadourny, R. and Jouzel, J., 1984: A general circulation model of water isotope cycles in the atmosphere. Nature 311: 24-29.

For full references please consult:

www.pages-igbp.org/products/newsletters/ref2002_2.htm

\section{Towards a Regional Synthesis of Mediterranean Climatic Change Using Lake Stable Isotope Records}

\section{Neil Roberts and Matt Jones}

ISOMED working group, Quaternary Environments Research Group, Department of Geographical Sciences, University of Plymouth, UK; cnroberts@plymouth.ac.uk; m.jones-4@plymouth.ac.uk.

The Mediterranean basin is a climate-sensitive region with an exceptionally long and rich history of human use and abuse, stretching back to the advent of Neolithic farming in Southwest Asia around $10 \mathrm{kyr}$ ago. These factors have led to a great interest in the environmental history of the region, especially through the last glacial-interglacial transition and the Holocene. However, the long and complex history of cultural-envi- ronmental relations has created some difficulties in distinguishing climate change from human impact in many palaeoenvironmental proxy records, for example through pollen analysis .

Unlike pollen, isotope-based records from non-marine settings are unlikely to be compromised by human impact, and a substantial volume of work from continental archives from the region is now appearing in the literature, in par- ticular from lake records (Fig. 1). This number of isotope records has the potential to allow comparison of environmental change across the Mediterranean basin. However, which specific climatic and environmental factors drive the changes in stable isotope ratios - as measured from various biogenic and authigenic fractions of lake sediment - remains under debate. 


\section{Science Highlights}

\section{Possible Controls on Isotope Values}

One common feature of records for all but the most dilute, short residence-time lakes is a shift to more negative $\delta^{18} O$ values during the late Pleistocene to early Holocene climatic transition (Fig. 2 ). Such a shift is precisely the reverse of the isotopic trend which characterises the same transition in lakes from the Alpine region and most of Central Europe and therefore demonstrates the relative unimportance of temperature as a driver of Mediterranean lake isotopic records over this time scale. A similar oxygen-isotope shift occurred in lakes at start of the last (MIS 5e) interglacial, and is also a feature of cave speleothem records, for example from Israel.

This leads to two main questions; firstly, if temperature is not the primary driver of isotope change in Mediterranean lake waters what is? Secondly, are all Mediterranean lakes driven by the same primary controlling mechanism?

Evaporation is an important factor in Mediterranean lake-water balance, particularly in the summer months. Lakes which have no outflow lose most of their water through evaporation and this has been shown to be a major factor in controlling both oxygen and carbon stable isotope values (Talbot, 1990). However, lakes which have an outflow and cannot therefore be classed as hydrologically "closed" systems, have none the less been shown to be evaporatively enriched in 180 during the summer months (Leng et al., 1999). This is probably due to the seasonal water balance in the lake, with evaporation being the dominant pathway for water loss during the summer, the time of the year when most authigenic carbonates are precipitated. Lakes may also become seasonally "closed" with surface outflow cut off due to lakelevel fall during summer months. Significantly, these open but isotopically-enriched lakes have stayed chemically dilute. This means that

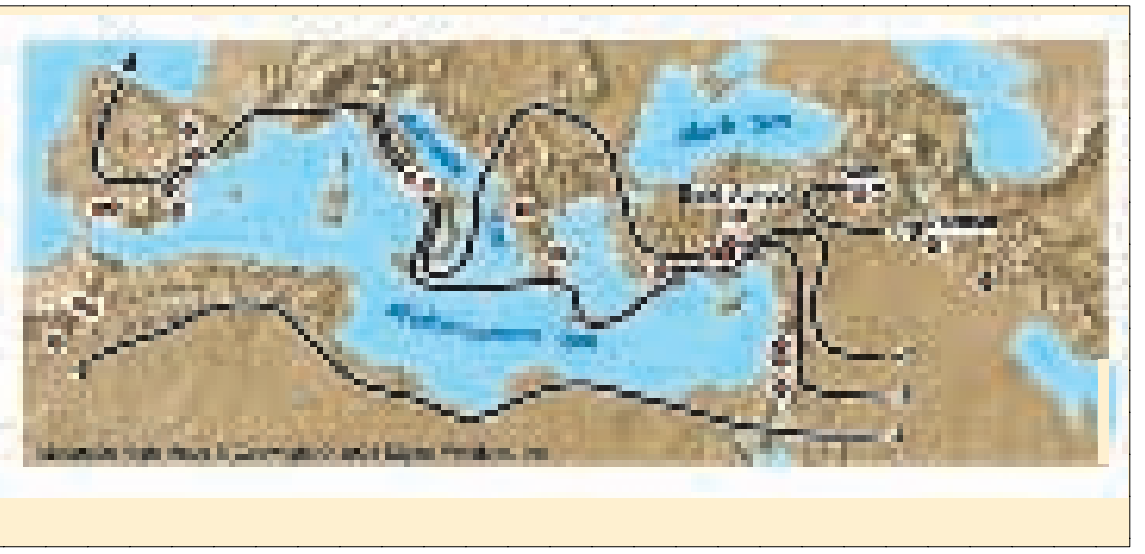

Fig. 1: Map of Late Quaternary lake-sediment stable isotope sites from the Mediterranean. Isolines show the mean weighted $\delta^{18} \mathrm{O}$ composition of precipitation inferred from IAEA data.

isotope-based methods may have a different, and lower, sensitivity threshold to lake water-balance changes than those based on measured or inferred lake salinity.

The flip side of the evaporation coin is precipitation. A positive shift in a stable isotope record could be due to a reduction in precipitation input to the system instead of - or as well as - an increase in evaporation. Stable isotope records from dryland regions have therefore often been interpreted as changes in the precipitation:evaporation ratio $(P: E)$, although it remains unclear which of the two plays the more important part in this ratio isotopically. Nor is the dominant climatic control over the amount and stable isotope composition of evaporation currently well understood.

Changes in rainfall seasonality, too, may have a significant effect on lake-water oxygen isotope values. Particularly at the eastern end of the Mediterranean basin, in a more continental setting, the differences between isotope values of summer and winter rains are large. Any change in the ratio of the amount of rainfall between these times would have a significant impact on the initial value of the waters entering the lake system.

Finally, the isotope composition of the precipitation source, especially over glacial - interglacial time scales, will also regulate the isotope value of precipitation. Mediterranean Sea waters follow the global oceanic shift from more positive to more negative isotope values during glacial - interglacial transitions, and this may explain some of the changes observed in the lake records. On shorter time scales, marine events such as sapropel formation (as occurred during the early Holocene) can be linked to significant changes in sea-water oxygen isotope values.

All these factors, along with temperature, will affect the isotope values of lake waters and the resulting values of the carbonate preserved in the sedimentary record. The dominant control on the system will vary from lake to lake and over different time scales, and requires an understanding of the site-specific isotope hydrology of each lake basin.

\section{Regional Trends}

Even with a range of possible factors controlling the changes in each lake isotope record, common trends do appear in different lake sediment records from across the region. However, although records show similar trends, the shifts in isotope values have been interpreted differently from site to site. Figure 2 shows the $\delta^{18} \mathrm{O}$ records from three East Mediterranean lakes lying in comparable climatic settings. In these examples, the negative shift in $\delta^{18} O$ at the beginning of the Holocene at Eski Acıgöl and Zeribar has been interpreted as indicating a rapid increase in precipitation at this time (Roberts et al., 2001; Stevens et al., 2001), while at Lake Van it has been linked to an increase 


\section{Science Highlights}

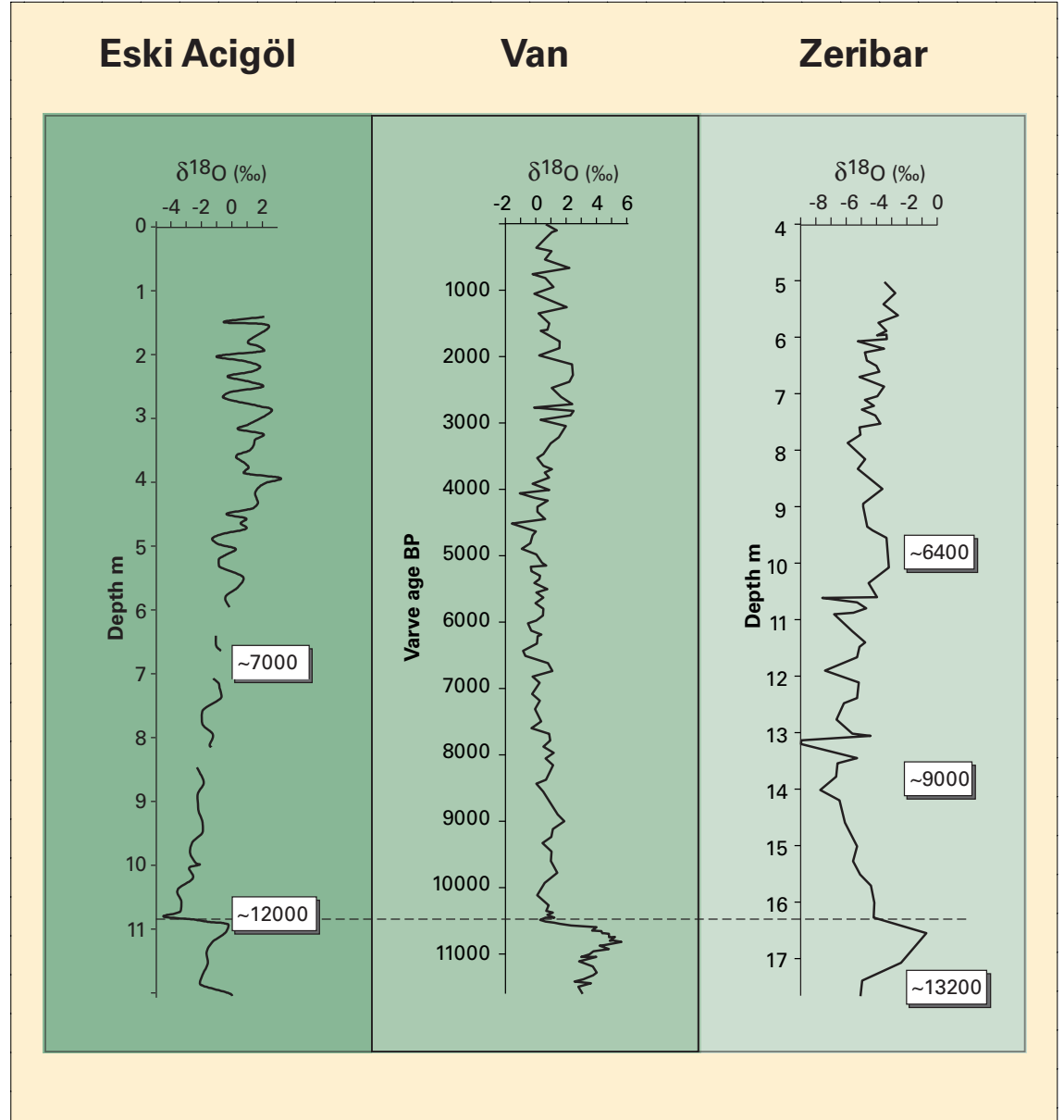

Fig. 2: $\delta^{18} \mathrm{O}$ records for the last $\sim 12 \mathrm{kyr}$ for three East Mediterranean lakes. The data are plotted on similar depth scales, with dates in calendar years BP. The dashed horizontal line marks the Pleistocene-Holocene boundary. Data from Roberts et al. (2001), Lemcke and Sturm (1997) and Stevens et al. (2001).

in relative humidity (Lemcke and Sturm, 1997).

A second common trend in lake records is towards more positive oxygen isotope values during the second half of the Holocene, although the precise timing of this shift appears to vary between sites. For the three lakes shown in Figure 2 rather different explanations have been proposed to explain this trend. The records from Eski Acıgöl and Van have been interpreted as representing drier climatic conditions during the later Holocene, via declining regional groundwater levels and decreasing relative humidity, respectively. In both cases, the interpretations of the stable isotope data are supported by other proxy-climate evidence of changes in water levels and salinity. The inferred wetter early-mid Holocene conditions in these lake records would have partly coincided with the last period of Mediterranean Sea sapropel formation. By contrast, the Holocene isotopic record from Zeribar has been inferred to represent primarily changes in rainfall seasonality, rather than the $\mathrm{P}$ : E ratio (Stevens et al., 2001). Support for this interpretation comes from the fact that diatom, cladocera and plant macrofossil data indicate that Lake Zeribar waters have stayed dilute throughout the last $\sim 11 \mathrm{kyr}$, and that absolute $\delta^{18} \mathrm{O}$ values are more negative than at the other two lakes.

\section{Conclusions}

Due to the large number of possible controls on lake-water stable isotope values it is important that each site is interpreted independently. Knowledge of the modern stable isotope hydrology and comparison with other proxies from the same sediment sequences should allow controls on stable isotopes to be better understood.
It appears that even though potentially controlled by different dominant factors, the resulting stable isotope trends for lakes in the Mediterranean are similar through the deglacial transition as well as through the Holocene. The negative shift in $\delta^{18} \mathrm{O}$ at the beginning of the Holocene discounts temperature being a dominant control on Mediterranean lake systems, at least on long (>10 kyr) time scales. Indeed Mediterranean lake isotope trends share more in common with those in Africa and Tibet than they do with those in central and northern Europe.

For these issues to be resolved comparison is needed with further isotope records from well-dated sequences so that the degree of synchroneity between these trends can be established, not only in lakes but also in other archives of stable isotope hydrology such as speleothems and marine cores.

\section{REFERENCES}

Lemcke G. and Sturm, M., 1997: $\delta^{18} 0$ and trace element measurements as proxy for the reconstruction of climate changes at Lake Van (Turkey): preliminary results. In Third World Millennium BC Climate Change and Old World Social Collapse. Edited by H.N. Dalfes, G. Kukla and H. Weiss. NATO ASI Series, Series 1: Global Environmental Change, 49: 653-678.

Leng, M.J., Roberts, N., Reed, J.M. and Sloane, H.J., 1999: Late Quaternary palaeohydrology of the Konya Basin, Turkey, based on isotope studies of modern hydrology and lacustrine carbonates. Journal of Paleolimnology 22: 187-204.

Roberts, N., Reed, J., Leng, M.J., Kuzucuo_lu, C., Fontugne, M., Bertaux, J., Woldring, H., Bottema, S., Black, S., Hunt, E. and Karabıyıkolu, M. 2001: The tempo of Holocene climatic change in the eastern Mediterranean region: new highresolution crater-lake sediment data from central Turkey. The Holocene 11: 721-736.

Stevens, L.R., Wright, H.E., Jr. and Ito, E., 2001: Proposed changes in seasonality of climate during the late-glacial and Holocene at Lake Zeribar, Iran. The Holocene 11: 747-756.

Talbot, M.R., 1990: A review of the palaeohydrological interpretation of carbon and oxygen isotopic ratios in primary lacustrine carbonates. Chemical Geology (Isotope Geoscience Section) 80: 261-79.

For further details please consult the ISOMED web site:

http://www.geog.plym.ac.uk/research/groups/ is18omed.htm 


\title{
Past and Present Ecohydrology of the Peace-Athabasca Delta, Northern Alberta, Canada: Water Isotope Tracers Lead the Way
}

\author{
Brent B. Wolfe ${ }^{1}$, Thomas W.D. Edwards ${ }^{1}$ and Roland I. Hall ${ }^{2}$ \\ PAD research group, Departments of Earth Sciences ${ }^{1}$ and Biology ${ }^{2}$, University of Waterloo, Waterloo ON, Canada \\ bwolfe@uwaterloo.ca; twdedwar@uwaterloo.ca; rihall@uwaterloo.ca
}

The Peace-Athabasca Delta (PAD), situated at the confluence of the Peace and Athabasca Rivers at the western end of Lake Athabasca, is one of the world's largest freshwater deltas, containing a myriad of shallow lakes and wetlands, which support bountiful wildlife, including migratory waterfowl and a large population of North American bison. Although lying at boreal latitudes, the PAD constitutes a unique extra-limital prairie wetland complex ecologically, as well as being a key node in the Mackenzie River drainage system, the single largest source of freshwater discharge to the Arctic Ocean from continental North America. The PAD also has important indigenous and historical cultural significance and is recognized internationally as a UNESCO World Heritage Site.

Extensive multidisciplinary research efforts are being conducted to gain better understanding of the present and past ecohydrology of the PAD, with the aim of assessing the impact of both natural and anthropogenic factors, ranging from climatic variability and change to the influence of river flow regulation resulting from hydroelectric power generation at the headwaters of the Peace River (Prowse and Lalonde, 1996; Timoney et al., 1997; Cohen, 1997). The latter is of particular interest because of the possibility that alteration of the discharge characteristics of the Peace River may be affecting the frequency and magnitude of spring ice-jam flooding, which plays an important role in the water balance of many lakes and wetlands that are perched above the level of other, more frequent, highwater events (e.g., see Prowse and Conly, 1998, 2000). This is an important consideration for effective longterm environmental stewardship of the PAD in the face of future climatic variability and change, as well as the likelihood of increasing demand for

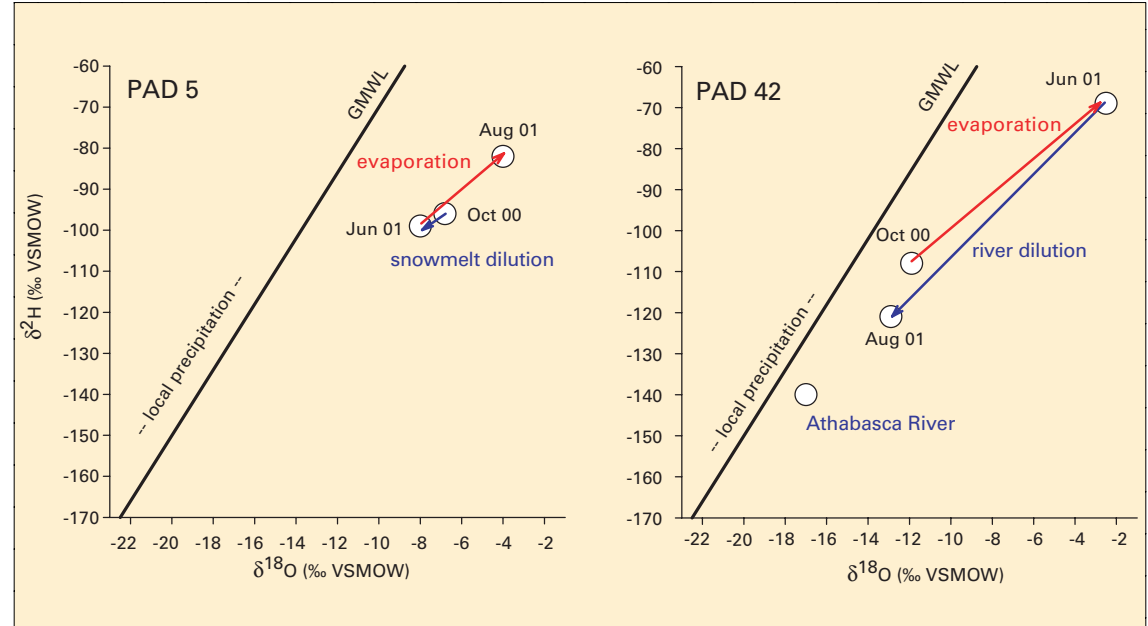

Fig. 1: $\delta^{18} \mathrm{O}-\delta^{2} \mathrm{H}$ plots showing temporal variations in the isotopic composition of two PAD lakes sampled on three occasions, at ice-on in October 2000, and relatively early and late in the open-water season in June and August 2001. As noted in the text, although similar in morphology and exposed to identical meteorological conditions, the two water bodies exhibit strikingly different isotopic evolutions. Such highly lake-specific effects need to be carefully considered in the interpretation of stratigraphic records of water isotopes, as well as other biological, physical and geochemical tracers

hydroelectric power and consumptive water use.

Our studies of the modern ecohydrology are spearheaded by utilization of the water isotope tracers ${ }^{18} \mathrm{O}$ and ${ }^{2} \mathrm{H}$ to assess instantaneous water balance in selected lakes and especially to detect events such as high-water flooding, which is difficult to monitor directly because of the remote setting and extremely subdued topography of the PAD. Information about the present hydrologic status and variability of lakes is crucial to the interpretation and calibration of other biological, physical and geochemical indicators (e.g., diatoms, plant macrofossils, pigments, $\mathrm{C}$ and $\mathrm{N}$ elemental and isotopic composition of organic matter, sediment granulometry and geochemistry), which are being used in company with oxygen isotope data from aquatic cellulose to reconstruct the history of selected PAD lakes from sediment cores.

An impression of the dynamic and individualistic behaviour of lakes in the PAD can be gained from the $\delta^{18} \mathrm{O}-\delta^{2} \mathrm{H}$ crossplots for sequential sampling of lakes PAD 5 and PAD 42 shown in Figure 1. PAD 5, a shallow $(\sim 1 \mathrm{~m})$ perched lake in a forested part of the Peace sector that normally receives river water only in the event of major ice-jam floods, reveals significant changes in isotopic composition between sampling episodes in October 2000, June 2001 and August 2001. Slight depletion in heavy-isotope content between October 2000 and June 2001, attributable to dilution by local precipitation (mostly snowmelt), was followed by progressive evaporative enrichment over the summer captured by the sample obtained in August 2001. PAD 42 , a lake of comparable size and depth in a sparsely forested area in the Athabasca sector having frequent river connection, on the other hand, behaved in a strongly contrasting manner, marked by pronounced heavy-isotope enrichment between October 2000 and June 2001 due to the overwhelming influence of evaporation on the water balance of the lake after ice-off in the spring, in spite of contributions from snowmelt runoff. This was followed by a profound shift to lower values by August 2001, obscuring the effects of seasonal evaporation, deriving from a mid-summer high-water event in 


\section{Science Highlights}

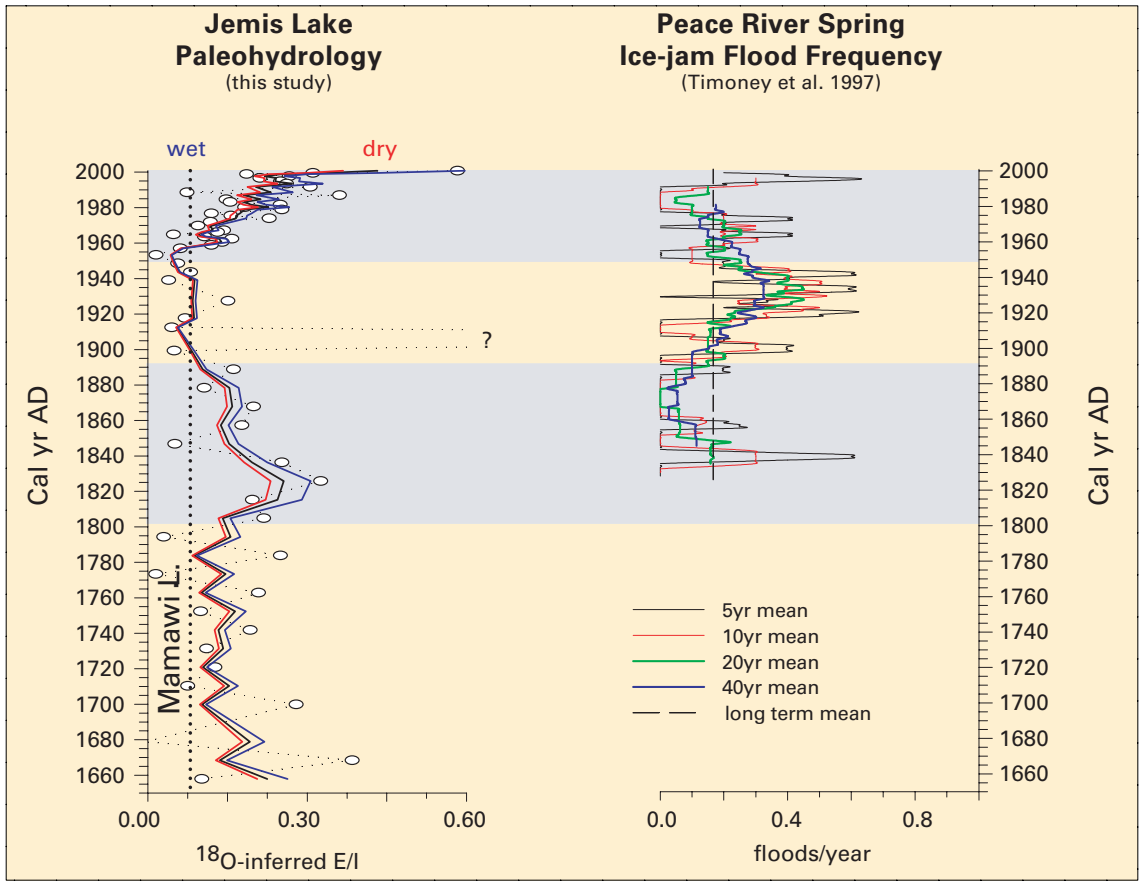

Fig. 2: Comparison of isotope-inferred water balance (expressed as evaporation/inflow ratio, E/I) of Jemis Lake with Peace River ice-jam flood frequency reconstructed from observational and anecdotal evidence by Timoney et al. (1997). Two multi-decadal periods of relatively dry conditions (high average E/l, marked by shaded zones) in Jemis Lake and persistently low icejam flood frequency have apparently occurred within the past 175 years, with the current dry phase beginning in the mid-1900s. [Note: This first-order estimation of paleo E/I ratios for Jemis Lake is based on variations in measured $\delta^{18} \mathrm{O}$ of aquatic cellulose, assuming "Craig-type" evaporative enrichment of lake waters fed by source waters of constant isotopic composition (e.g., see Gibson, 2001, Wolfe et al., 2001a, b). The modelled values are smoothed by a threepoint running mean, and assume an ice-free season relative humidity of $55 \pm 10 \%$ (black line bracketed by red and blue). The modern E/l ratio for nearby Mamawi Lake (vertical dashed line) provides a reasonable lower limit, since non-flood intervals should be marked by disconnection from this river-fed lake.]

the Athabasca River that recharged the lake with isotopically-depleted river water.

Insight gained from such observations is key to the task of reconstructing the paleohydrology of the PAD over various time periods, which is necessary to provide the context for assessing ongoing change and evolution of the system. Preliminary results from stratigraphic analysis of a short sediment core from Jemis Lake, for example, suggests that changing water balance in this lake, as inferred from aquatic cellulose $\delta^{18} \mathrm{O}$, may provide a rough proxy for ice-jam flood frequency on the Peace River, which appears to have fluctuated widely over the past several centuries (Fig. 2). Fuller integration of other multiproxy evidence is certain to refine and sharpen this isotopic tool appreciably (e.g., see Wolfe et al., 2002), as we delve deeper into the paleo-history of the PAD, as well as in extended studies planned over the coming years in the Slave and Mackenzie deltas, downstream.

\section{ACKNOWLEDGEMENTS}

We wish to thank the British Columbia Hydro and Power Authority, the Natural Sciences and Engineering Research Council of Canada, the staff of Wood Buffalo National Park, and Indian and Northern Affairs Canada for support of this research, and especially for the training opportunities it affords our students.

\section{REFERENCES}

Cohen, S.J., 1997: What if and so what in northwest Canada: Could climate change make a difference to the future of the Mackenzie Basin? Arctic $\mathbf{5 0}$ : 293-307.

Gibson, J.J., 2001: Forest-tundra water balance signals traced by isotopic enrichment in lakes. Journal of Hydrology 251: 1-13

Prowse, T.D. and Lalonde, V., 1996: Open-water and ice-jam flooding of a northern delta. Nordic Hydrology 27: 85-100.

Prowse, T.D. and Conly, F.M., 1998: Impacts of climatic variability and flow regulation on ice-jam flooding of a northern delta. Hydrological Processes 12 : $1589-1610$.

For full references please consult:

www.pages-igbp.org/products/newsletters/ref2002_2.htm

\section{Lacustrine 0xygen Isotopic Records from Temperate Marl Lakes}

Richard T. Jones ${ }^{1}$ and Jim D. Marshall 2

"Hawes Water Research Group" Departments of Geography' and Earth Sciences², University of Liverpool, Liverpool, L69 3BX, UK.; rtjones@liv.ac.uk, isotopes@liv.ac.uk

Sediments from small, temperate, carbonate lakes can provide excellent archives for Late Glacial and Holocene paleo-environmental investigations. The rapid reaction of the local hydrological system to environmental change, coupled with relatively high sediment accumulation rates, facilitate high-resolution stratigraphic studies that can employ a wide range of lithological, chemical and biological proxies. Stable isotopic data can be collected relatively easily from authigenic carbonates, which precipitate in the water column, and from the calcareous skeletons of macro and micro-fossils. Ostracods that inhabit different lacustrine settings and which calcify at different times of the year potentially enable seasonal and depth variations to be determined. Carbonate oxygen isotopic data is particularly useful in that it can provide a record that can be linked to changes in temperature and meteoric precipitation on a scale that can be directly correlated with ice-core records. Because water residence times are short these isotopic records also can be used as a proxy for 'instantaneous' climate forcing - enabling the identification of lag effects and non-linear changes in other proxies which are controlled by processes acting within the lake catchment.

Sediments from several small hard-water lakes are the focus of current investigations funded by the Natural Environment Research Council. The sediment records are being calibrated by the investigation of carbonate precipitation and isotopic variation in the modern lakes (Fig. 1) and a multiproxy investigation in- 


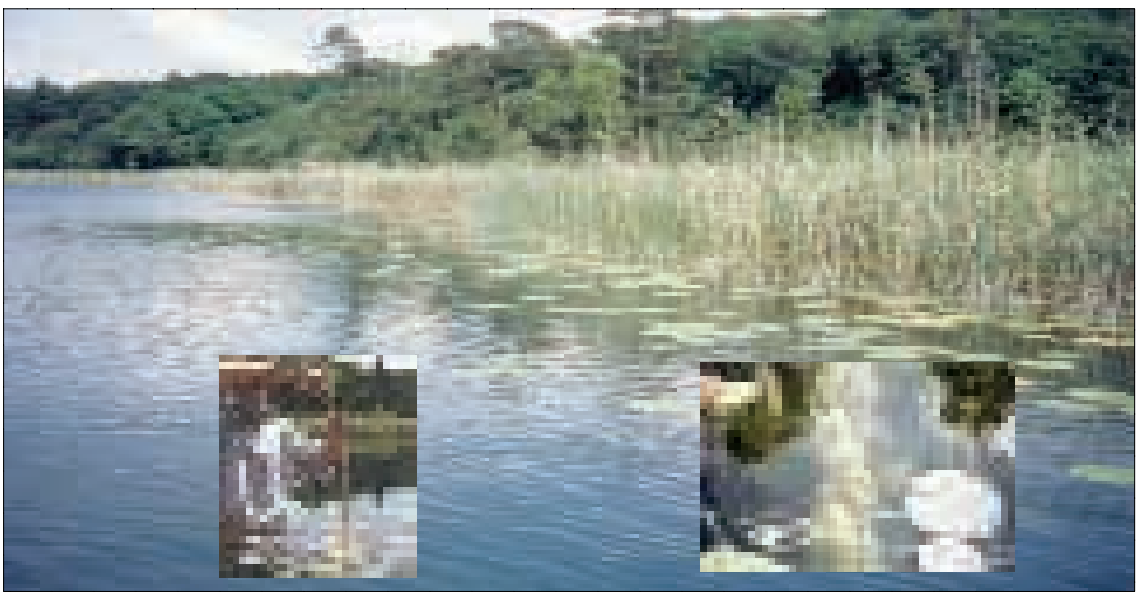

Fig 1: Photographs of Hawes Water, NW England. Carbonate precipitation is mediated by photosynthesis. Site monitoring enables determination of the season of carbonate precipitation and the local relationship between temperature, water and carbonate compositions.

volving detailed study of pollen, chironomids and sediment properties.

\section{Local Calibration and Verification of Oxygen Isotopic Records}

Figure 2 illustrates the factors that can influence the oxygen isotopic composition of a carbonate precipitated in freshwater. If a carbonate precipitates in equilibrium with its environment its oxygen isotopic composition depends primarily on the ambient temperature and the isotopic composition of the local water. For fossil sedimentary carbonates, if either water compositions or temperature of precipitation is known or can be estimated, equilibrium equations enable calculation of the 'unknown' (temperature or water composition). In the absence of 'known' values; relative changes in temperature or the isotopic composition of the water can be calculated.

An understanding of the conditions under which carbonate precipitation takes place in the modern lake is thus critical to understanding the sediment record. Equilibrium precipitation cannot be assumed for either biogenic or authigenic precipitates in natural environments: local (even within-organism) changes in $\mathrm{pH}$, speciation and supersaturation may influence isotopic fractionation. Studies of the isotopic systematics of inorganic and biogenic carbonate precipitation in modern lakes can be used to provide a local verification of the sediment record by constraining the data from sediment cores.
In the case of Hawes Water, for example, extensive monitoring of the lake chemistry, temperature, saturation state and carbonate precipitates has been carried out over a two-year period. The carbonate precipitates in the summer months and in the surface waters of the lake. The sedimentary record will therefore preferentially record changes in summer/surface conditions. Carbonate saturation states in the modern lake are never high enough for direct inorganic precipitation. The precipitation of carbonate is mediated by the photosynthesis of both macrophytes and algae and most of the micrite forms on plant and algal substrates (Fig. 1). By carefully taking sediment samples and monitoring water compositions it has been possible to determine that the carbonate values approach those of inorganic equilibrium. However there appears to be a systematic offset, and a slightly reduced temperature gradient, which may be associated with kinetic effects (Fig. 3). We have thus successfully determined a local temperature/water composition relationship that can be used in the interpretation of the sediment records.

The PAGES-ISOMAP initiative highlights the climatic importance of mapping the isotopic composition of meteoric water as a variable that can be directly modelled by global climate models. Lake water compositions are likely to dominantly reflect the composition of local rainfall but local effects - including evaporation (in the recharge zone and from the lake itself), water/rock interaction and differential mixing or separation of seasonal rain may influence the composition of a particular lake. It is important to understand possible temporal variation in the lake isotopic compositions (Fig 2). Unlike closed lakes at low latitudes, evaporation effects are likely to be minimal in temperate conditions. However, in lakes that become thermally stratified, like Hawes Water, the isotopic composition of the water becomes stratified as summer rainfall (with markedly higher $\delta^{18} \mathrm{O}$ than the annual mean) is preferentially kept in the surface waters during the season of carbonate precipitation. Such effects lead to an enrichment of $~ 1 \%$ 。 in the surface waters.

\section{Late Glacial Data - Climatic Significance}

The Late Glacial oxygen isotope record from Hawes Water (Fig. 4) illustrates the sensitivity of temperate marl lakes to environmental change. The $\delta^{18} \mathrm{O}$ record clearly distinguish-

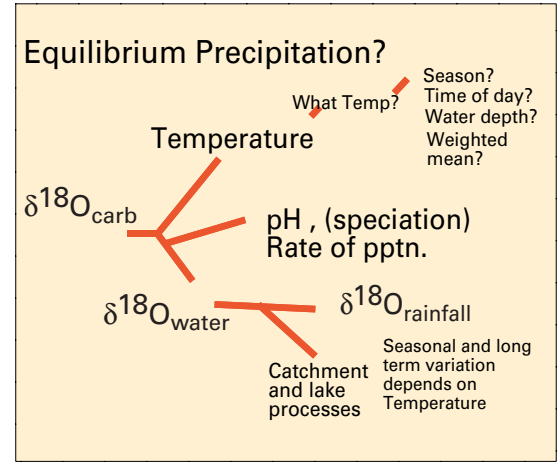

Fig. 2: Factors that can influence the oxygen isotopic composition of lacustrine carbonates.

es the cold Younger Dryas stadial from the preceding and much warmer Late Glacial interstadial. The structure of the Younger Dryas isotopic excursion suggests rapid cooling followed by an early phase of warming that long preceded the major warming that ended the stadial. This structure is also recognised in the GRIP ice-core record. The longerterm pattern also records four shortlived cold events in the interstadial (A-D on Fig. 4). The pattern has close parallels with those from the high-resolution chironomid temperature record from southern Scotland (Whitrig Bog; see Brooks and Birks, 2000), the ostracod isotopic re- 


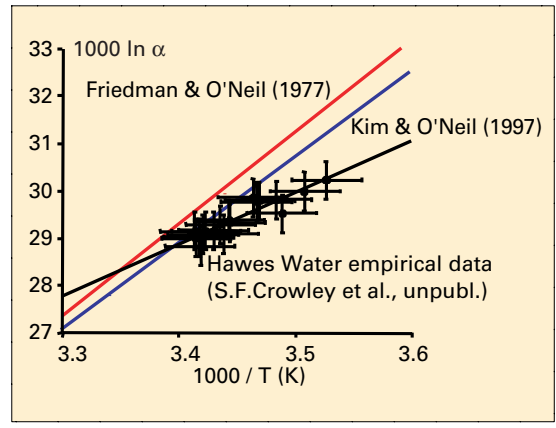

Fig. 3: Locally determined isotopic fractionation for carbonate precipitates at Hawes Water compared to published equilibrium relationships.

cord from Ammersee in central Europe (von Grafenstein et al., 1999), and the GRIP ice-core record (Fig. 4). Interestingly, although the overall pattern of change is similar there are some apparent discrepancies between the relative timing of the interstadial optimum and the relative magnitude of the interstadial events. These may be significant in terms of the detailed climate dynamics of the north Atlantic region.

A discussion of the Hawes Water results in terms of changes in temperature and meteoric water compositions will be published shortly (Marshall et al., in press). Simple calculations imply significant fluctuations in both temperature and meteoric water compositions during the interstadial and Younger Dryas. Significantly, changes in temperature calculated from the isotopic record are similar to those derived for the UK from Coleopterid records and the marine Atlantic diatom record. However they are significantly greater than those derived from the Chironomid palaeothermometer at Whitrig Bog. There is clearly a need to resolve this apparent discrepancy between the proxies if we are to develop a quantitative understanding of climate change. Ideally, chironomid and isotopic data are needed from the same archive and at the same resolution. Most chironomid studies and the entire calibration training set used to develop the temperature inference model are based on data from soft-water, relatively acidic lakes. As a first step to resolving the problem we are currently trying to obtain a high-resolution chironomid record for the Hawes water site.
Many indicators of climate change, such as pollen or changes in detrital sediment input, take time to react to changes in local climate. Alternatively, there may be no reaction to climate change at all until a critical threshold has been reached. The isotopic composition of carbonate precipitated in small lake systems with relatively short water residence times will, however, react rapidly to changes in climate that affect the local temperature or the isotopic composition of the water. The oxygen isotopic record may thus provide a proxy that records a more or less instantaneous response to climate records can be minimised by sitespecific calibration exercises to ascertain whether carbonate froms in equilibrium and to determine the current conditions of carbonate formation. Given independent highresolution monitors of temperature change, like those from chironomid or coleopteran transfer functions, it will be possible to use the oxygen isotopic records as a direct measure of changes in the isotopic composition of precipitation. These records will provide crucial data for evaluating and refining global climate models.

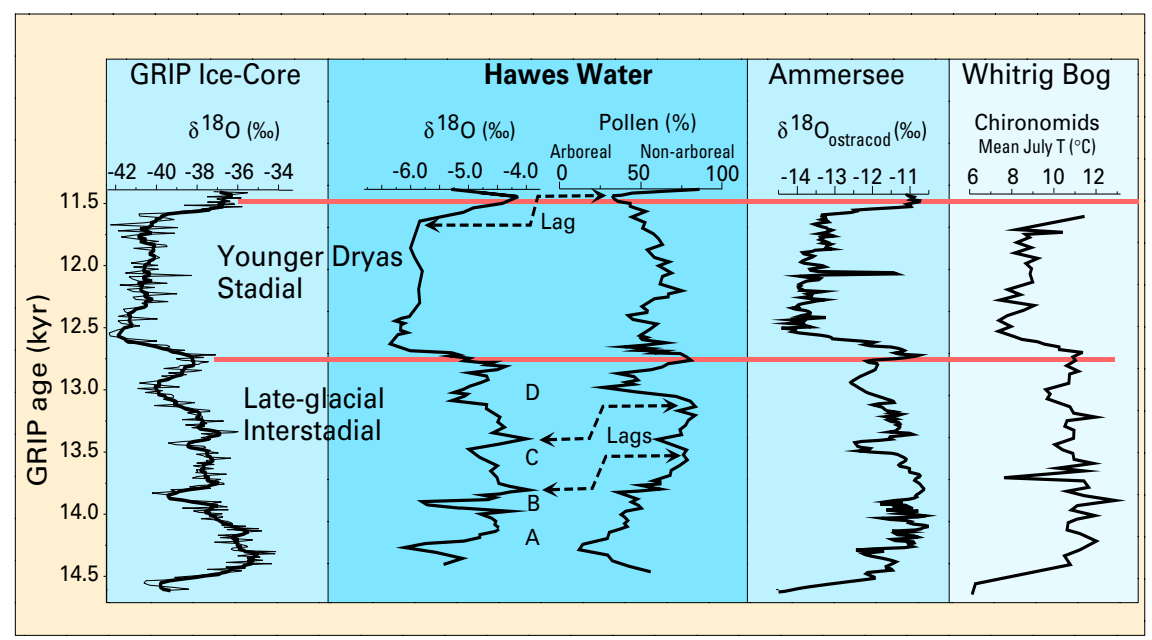

Fig. 4: Late Glacial isotopic and floral data from Hawes Water NW England compared to the GRIP ice-core $\delta^{18} \mathrm{O}$ record, the Ammersee ostracod record and the Whitrig Bog chironomid temperature reconstruction.

forcing. By comparing the isotopic record of environmental change at Hawes water with a detailed record of changes in the catchment, using pollen and magnetic analysis, it has been possible to identify differences in response times for different elements of the flora as well as for input of detritus (Jones et al., in press). Figure 4 shows an example of the lag effects associated with colonisation of the Hawes Water catchment following the end of the Devensian glaciation.

\section{Conclusions}

Sediments deposited in small, hard-water lakes can produce highresolution isotopic records of environmental change that respond directly and immediately to external climate forcing. Some of the problems with the quantitative interpretation of the oxygen isotopic

\section{REFERENCES}

Brooks, S.J. and Birks, H.J.B., 2000: Chironomidinferred late-glacial air temperatures at Whitrig Bog, Southeast Scotland. Journal of Quaternary Science 15: 759-764.

Jones, R.T., Marshall, J.D., Crowley, S.F., Bedford, A. Richardson, N. Bloemendal, J and Oldfield, F., in press.: A high resolution, multi-proxy Lateglacial record of climate change and intrasystem responses in NW England. Journal of Quaternary Science.

Marshall J.D., Jones, R.T., Crowley, S.F., Oldfield, F., Nash, S. and Bedford, A., in press: A high-resolution Late Glacial isotopic record from Hawes Water, NW England: climatic oscillations - calibration and comparison of palaeotemperature proxies. Palaeogeography, Palaeoclimatology, Palaeoecology.

von Grafenstein, U., Erlenkeuser, H., Brauer, A., Jouzel, J. and Johnsen, S.J., 1999: A Mid-European decadal isotope-climate record from 15,500 to 5000 years B.P. Science 284:1654-1657.

GRIP data: Greenland Summit ice cores CD ROM - GISP2/GRIP 1997. WDC-A for Paleoclimatology, NGDC, Boulder, Colorado, USA 


\section{Fire-Climate Linkages in the Mid-Latitude Americas}

Tucson, ARIzona, 23-28 March 2002

Climate, fire, and vegetation are interrelated elements of the earth system, and their variation and interaction through time have shaped the modern landscape. At annual and decadal scales and at the level of watersheds, climate/weather, vegetation composition, fuel buildup, and ignition frequency all determine the fire regime (i.e., the occurrence of fire, as well as its size and severity). On century and millennial temporal scales and landscape-to-regional spatial scales, however, climate determines both the fire regime and the potential vegetation composition. Consequently, the linkages between fire and vegetation are less clear on these long time scales.

Fire history and fire-climate linkages were discussed at this workshop attended by 70 scientists from Argentina, Australia, Canada, Chile, England, Mexico, Russia, Switzerland, and the United States. The purpose of the meeting was to bring together researchers who study past variations in fire activity as recorded by tree-ring and lake-sediment data and researchers who consider the climatic controls of fire. The similarities and differences between western North America and southern South America present an opportunity to study fire occurrence under an array of climate and vegetation conditions (Fig. 1).

Reconstructions of past fire occurrence during the last few centuries are based on tree-ring records and tree stand-age analysis, both of which offer high spatial and temporal resolution.

A second fire proxy, stratigraphic charcoal records from varved and non-varved lake and marine sediments, ice cores, peatlands, and soils have been used to reconstruct fire history across a range of latitudes. Because these records of fire activity span thousands of years, they provide information on the role of fire during periods of climate and vegetation change. Cathy Whitlock (United States) noted that highest fire activity in the Holo-

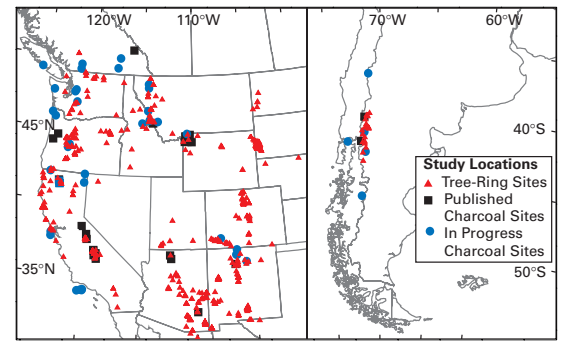

Fig. 1: Location of lake-sediment charcoal and tree-ring records from western North and South America.

cene was associated with centennial-to-millennial periods of drought, but the controls of fire on this time scale were sometimes overridden by shorter term variations. In northwestern North America, high fire frequency was associated with intensification of the subtropical high-pressure system, which occurred as a result of higher-thanpresent summer insolation in the early Holocene. In Patagonia, Maria Marta Bianchi (Argentina) and Patricio Moreno (Chile) showed highest fire activity (both frequency and magnitude) in the early Holocene and during the last few centuries.

The broad-scale climatic controls that give rise to conditions conducive to fires at the local scale were also described for North America and Patagonia by Patrick Bartlein (United States), Michael Flannigan (Canada), Tony Westerling (United States), Cary Mock (United States), Tim Brown (United States), and Henry Diaz (United States). The Iocation of mid tropospheric atmospheric pressure ridges, areas of rising air, and the seasonal variations in lightning occurrence are significant elements of western and northern North American fire climatology.

Fire and climate proxy records show a strong influence of annualto-decadal scale climate variability in fire occurrence. While the importance of El Nino-Southern Oscillation in the American Southwest and northern Patagonia was acknowledged, Ricardo Villalba (Argentina) emphasized that ENSO did not explain all fire variability on annual and decadal time scales.
The importance of retrospective fire-climate studies as a tool for fire management was also addressed. The legacy of past fires and periods of no fire also needs to be considered in strategies that attempt to restore forests to a prehistoric condition. While the effects of fire suppression policies are evident in low-elevation dry forests, fire history data suggests that fire suppression may have only limited impact in wet forests at higher elevation and along the coast, according to presentations by Carl Skinner, Alan Taylor, Peter Brown, and Fred Swanson (all from the United States). Moreover, projections of future climate changes indicate that fire activity in most regions will increase, suggesting the need for adaptive management in many regions.

Products of the workshop include the development of a firehistory database, a web page for further exchange of research ideas and public information, and a series of syntheses.

Sponsors of the workshop included the USDA Forest Service PNW Research Station, the IGBP Past Global Changes Program (PAGES), the U.S. Interagency Joint Fire Sciences Program, the NSF Earth Systems History Program (PEP-1 activity), the Inter-American Institute, and the University of Arizona.

\section{Cathy Whitlock \\ Patrick Bartlein \\ University of Oregon \\ Eugene, OR, USA \\ whitlock@oregon.uoregon.edu \\ bartlein@oregon.uoregon.edu}

\section{Thomas Swetnam}

University of Arizona

Tucson, AZ, USA

tswetnam@|trr.arizona.edu

This workshop report was edited substantially for brevity, a more comprehensive version is available on the PAGES website.

(http://www.pages.unibe.ch/ shighlight/shighlight.html) 


\title{
Linking the Continental Environmental Quaternary History of Southern Africa with Ocean Currents and Antarctica
}

\author{
Cape Town, South Africa, 15-17 May 2002
}

The main goals of this 3 day workshop were to identify the crucial gaps in understanding of ocean-continental climate links for southern Africa and the surrounding oceans, as well as to actively promote broader cooperation across disciplinary and international boundaries. The workshop was held to allow scientists from Europe to meet with colleagues and students from South African institutions, to discuss the scientific issues, to promote research efforts, and to encourage co-operation with the industries exploring natural resources along the South African margins. Participants were drawn from a broad spectrum of disciplines including oceanography, archaeology, geology, geography, palaeoclimatology, and botany.

An emerging focus in global palaeoclimate research is the nature of the links between ocean circulation and continental climate. This is an area of particular interest in southern Africa as it is strongly influenced by oceanic conditions. Connections between the Benguela upwelling system, the winter rainfall/summer drought climate, and the unique Fynbos flora of the West coast, as well as the warm Agulhas current and summer rainfall climate/savanna woodlands of the eastern and interior regions of southern Africa are apparent today. But we know little about how these links varied in the past, or indeed about variation of water masses in the tropical Indian, southern subantarctic and polar oceans. Such information is important because of the key role these oceans play in energy transport within the southern hemisphere and between hemispheres.

Day 1 began with a brief introduction on the chief elements of modern oceanographic conditions around southern Africa, followed by reviews of ongoing marine sediment work off the West coast. Closer to shore, the Orange River mudbelt (HODSA project) and the DeBeers exploration and palaeoenvironmental research were described. An overview of ongoing monitoring of the modern Benguela ecosystem completed the West coast session. Thereafter, attention turned to the modern and palaeo Agulhas Current system, and its teleconnection to climate change in Antarctica and the North Atlantic.

Discussions during day 2 centered around continental conditions and climatic links between ocean and continent. Topics included longterm fluctuations in summer season rainfall from the Tswaing crater sediment record, Kalahari dune mobility, stalagmite records, possible links to Antarctic circulation, vegetation histories and dust transport recorded in marine sediment cores. A provocative presentation on long-term floral evolution emphasized the roles of fire and atmospheric $\mathrm{CO}_{2}$ levels. Agreement emerged among several studies that there was a northward shift of the winter rainfall belt along the west coast under full glacial conditions. Archaeological and palaeontological evidence was used to examine direct links between marine conditions and those of the adjacent West coast in the Holocene and late Pleistocene. The final sessions revolved around emerging opportunities for new joint research projects over the next 2 to 3 years that are likely to evolve due to scheduled expeditions with British, French, German and Spanish research vessels. One project will target extraction of a series of high resolution marine records from nearshore sites along the West coast, with clear links to coastal environments. Two complementary investigations will target transport of Agulhas waters and eddies, one focused on the retroflection area and the other on the SW Indian Ocean.

Day 3 was dedicated to the discussion of combining efforts within the framework of the different projects, and ways to strengthen international collaboration. It was agreed that the nature of ocean-continent connections effecting variability and history of marine systems and continental environments (Fig. 1) should

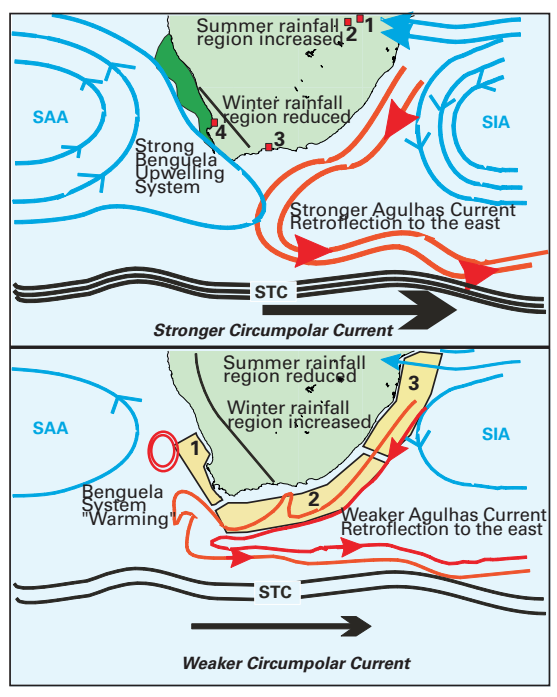

Fig. 1: Schematic view of atmospheric and oceanic processes driving South African precipitation patterns (Adapted from Cohen and Tyson 1995, and the ECRAN project UBordeaux). SAA and SIA are atmospheric South Atlantic and South Indian ocean Anticyclones, STC is Subtropical Convergence Zone. The red squares in the upper panel denote examples for land climate archives 11: Cold Air Cave, 2: Tswaing crater, 3: Nelson Bay Cave, 4: Steenbokfontein/ Elands Bay Cave), while yellow boxes in the lower panel outline the areas of marine coring programmes anticipated in the next 2 years 11: West coast margin, 2: Agulhas passage, 3: Limpopo/Sambesi Fans).

be the major objective in the future, and that these should be considered within the broader context of Antarctic and North Atlantic changes. The workshop also concluded that a science plan following the workshop theme should be developed immediately. This should help to create a coherent international research strategy and encourage support by potential partners from industries, funding agencies and political institutions.

We thank the workshop participants for their contributions and the National Research Foundation of South Africa and PAGES for financial sponsorship of the workshop.

\section{JULIA LEE-THORP}

University of Cape Town, South Africa; jlt@beattie.uct.ac.za

\section{RALPh SchNeideR}

Bremen University, Germany: rschneid@uni-bremen.de 


\section{PAGES Data Board Meeting}

Kandersteg, SWitzerland, 4-6 March 2002

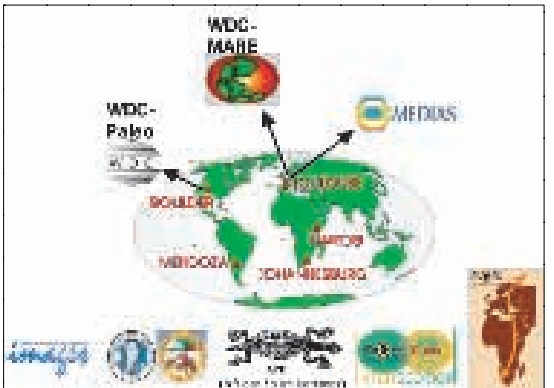

Fig. 1: Many of the data centers and data activities that are part of the PAGES Data system.

At the inaugural meeting of the new PAGES Data Board a list of planned actions and data policies was drawn up. Members in attendance at the inaugural meeting included representatives from all of the major data archives such as The World Data Center for Paleoclimatology in Boulder, USA, the World Data Center for Marine Environmental Data and PANGAEA in Germany as well as MEDIAS-France. In addition, representatives from thematic data collection efforts such as the African, European and North American Pollen databases and the IMAGES program were also present. Although participation in the workshop was necessarily limited, membership in the PAGES data board is open to all interested scientists and organizations. A full list of the proposed new PAGES Data board policies, which have subsequently been approved by the PAGES Scientific Steering Committee, is available on our web- site www.pages-igbp.org. Here we highlight a few of the major outcomes of the meeting:

Members of the PAGES Data System will work to encourage and facilitate access and exchange of paleoenvironmental data by:

- establishing networks for data management,

- providing tools to facilitate data contribution and improve data utility, and

- increasing data sharing through development of common formats for data and metadata interchange

New members are always welcome in the PAGES Data System, their management activities should:

- be developed in coordination with existing data management programs and centers (Fig. 1)

- use existing databases and systems where appropriate,

- use the metadata profiles and interchange systems approved by the PAGES Data Board for paleometadata management and exchange,

- establish a protocol to define the expected flow of data from scientists, through discipline or project based data programs, to long-term archive, and

- fully document data following established standards for metadata and data.

In the near future, members of the Data Board will cooperate to create a web based metadata portal compatible with, and linked to, the data archives maintained by all members. This portal, which will be mirrored by all the participating organizations including the PAGES IPO, will allow scientists to search for, or submit, any type of quantitative paleodata using simple keywords. This tool will allow fast and easy access to paleodata archived around the world.

The success of this initiative depends on the cooperation of various database managers, which was achieved during this first Data Board meeting, but more importantly, it depends on the willingness of individual scientists to submit their data to a participating archive. As one way to support this initiative, PAGES will request that the data used to create any figure published in a science highlights in PAGES News, be made publicity available in a participating data archive.

ISABELLE LAROCQUE

PAGES IPO, Bern Switzerland

larocque@pages.unibe.ch

\section{MARK EAKIN}

World Data Center for

Paleoclimatology, Boulder, USA

mark.eakin@noaa.gov

\section{Michael Diepenbroek}

Alfred Wegener Inst. for Polar\&Marine

Research,

Bremerhaven, Germany

mdiepenbroek@pangaea.de

\section{PAGES Meeting on High Latitude Paleoenvironments}

\section{Moscow, Russia, 16-17 MaY 2002}

Studies of environmental changes in the Arctic region are important not only for understanding vegetation and climate history inside the polar circle, but over the entire Earth. This PAGES meeting in Moscow brought together over 100 palaeoscientists working in northern Eurasia. The twoday schedule included 25 keynote lectures and more than 80 poster presentations. A wide variety of topics - from global carbon balance to climatic influences on ancient Egyptian society - covering geographical regions from the Barents Sea to the Tian-Shan Mountains and from Ukraine to Kamchatka - were covered, making it difficult to write a consistent overview. Unlike conventional meetings on High Latitude Environments, this meeting specifically sought to bring together the results obtained by the research teams of the former USSR, in collaboration with foreign partners, during the last ten years.

In the opening lecture Keith Alverson (Bern, Switzerland), provided an overview of PAGES and called for greater participation from the Russian and eastern European paleoscience communities. Eugene Vaganov (Krasnoyarsk) and Stepan Shiyatov (Ekaterinburg) presented results and perspectives from dendrochronological studies in the Urals and Siberia. These include full Holocene tree-ring chronologies and seek to reconstruct annually resolved temperature variatiability from tree-ring data. Significant shifts of the timberline in the Polar Ural Mountains was shown to 


\section{Workshop Reports}

have occurred during the historical period. The upper limit of tree growith is dated to mid-thirteenth century $A D$ and the lower to the end of nineteenth century AD. These timberline oscillations reflect changes in summer temperatures. As a further example, a 7310 year long chronology (from 5309 BC to 2000 AD) derived from more than 2700 samples of Siberian larch collected along the modern timberline in Yamal Peninsula was presented by Rashit Hantemirov (Ekaterinburg).

Lake and peat deposits were also presented as important palaeoenvironmental archives in northern Eurasia. The Baikal Drilling Program first demonstrated the possibility of reconstructing continuous records of climatic and environmental changes in eastern Siberia over the last 10 million years. Eugene Karabanov (Columbia, USA) and Elena Bezrukova (Irkutsk) debated the Pleistocene-Holocene history of the Baikal region. The Lake Baikal data show many similarities, but also significant differences, when compared with the North Atlantic records. In particular, the diatom record suggests that the Baikal ecosystem did not recover from YD glacial stress until 8.1 kaBP, long after the end of the Younger Dryas cold period in North Atlantic records, furthermore the highest diatom productivity is observed from 2.4 to $1.0 \mathrm{kaBP}$ rather than in the mid-Holocene as in the Atlantic or West Siberian records.

Qualitative pollen-based reconstruction of Holocene climate fluctuations in the Russian Arctic was discussed by Dmitry Bolshiyanov (StPetersburg). He reported spatial and temporal differences in the climate patterns reconstructed for different sectors of the Arctic, suggesting that the environmental history of northern Eurasia was rather complex and that changes in Holocene climate did not occur simultaneously over the continent. The need for highresolution data to reconstruct different aspects of late Pleistocene glaciations, including the last glacial maximum, in northern Eurasia (particularly their size and climatic effects) was stressed by Valery Astak-

A

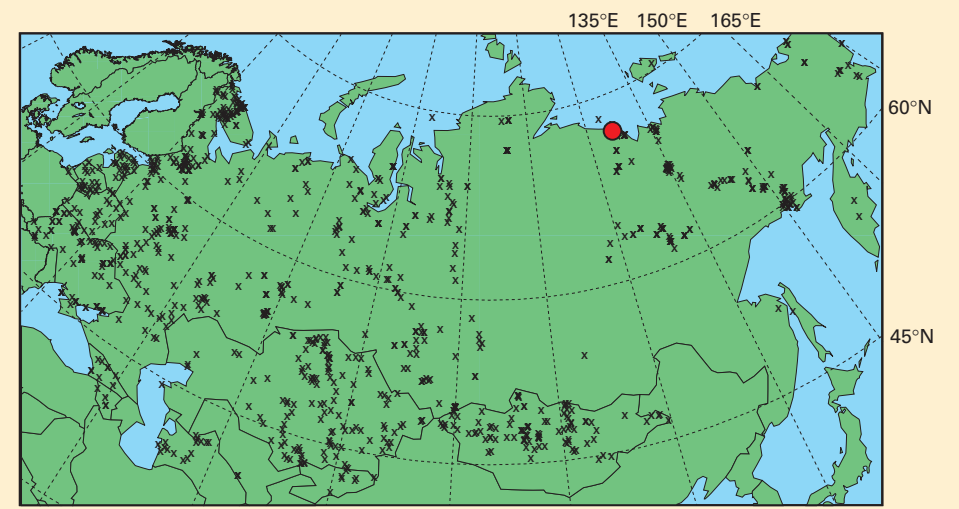

B
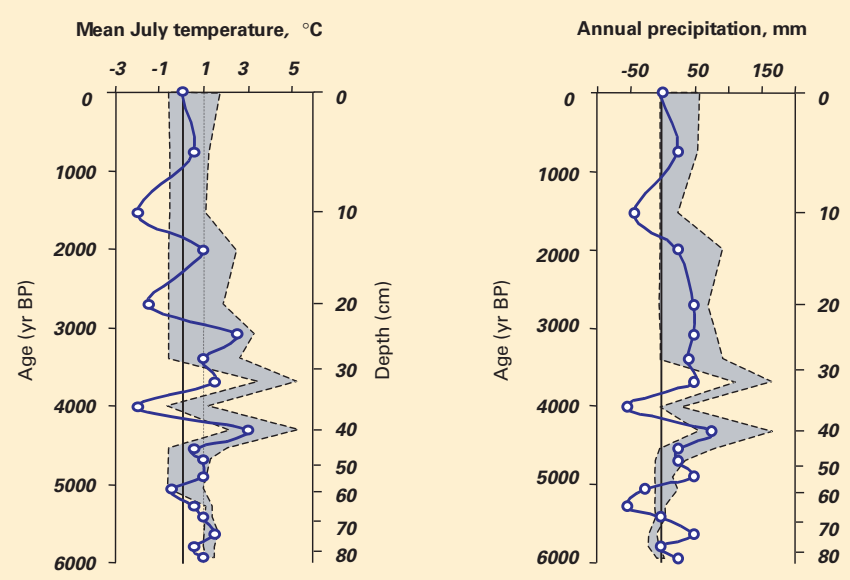

Fig. 1: A: Distribution of 1110 surface pollen samples from norhern Eurasia used as the reference data set to reconstruct climate from the fossil pollen record. B: Mean July temperature and annual precipitation (expressed as difference from modern climate) derived from Nikolay Lake pollen record $\left(73^{\circ} 20^{\prime} \mathrm{N}, 124^{\circ} 12^{\prime} \mathrm{E}\right.$, red dot on the map) with two statistical approaches: information-statistical method (blue line) and best modern analogue method (the range of most probable anomaly values is shown in grey, eight best analogues are considered for each fossil spectrum). From Andreev, A., Tarasov, P., Schwamborn, G. Ilyashuk, B. Ilyashuk, E., Bobrov, A., Klimanov, V., Rachold, V. and Hubberten, H.-W., submitted, High resolution Holocene paleoenvironmental records from Nikolay Lake, Arga Island, Lena River Delta, J. of Holocene.

hov (St-Petersburg) and several other speakers.

The results presented in Moscow indicated a wealth of regions in northern Eurasia, where palaeonvironmental studies have been intensively carried out over the past decade. However, for large areas of Central and Eastern Siberia and the Russian Plain as well as Middle Asia and Kazakhstan, we still need more high-resolution records in order to precisely reconstruct the timing and nature of Late Quaternary environmental variability in these regions (see e.g., Fig.1).Though the area of the former Soviet Union is no longer terra incognita for the international palaeoenvironmental community, significant gaps in understanding, such as the limits of the LGM glaciation and early to midHolocene monsoon-like circulation, still exist. Oksana Savoskul and
Pavel Tarasov (Moscow) pointed out that a future strategy for obtaining new, high-resolution data should be combined with the collection and critical evaluation of existing palaeoenvironmental records published in Russian papers and reports. In part towards this end, the meeting chair, Olga Solomina together with Keith Alverson at the PAGES IPO, are planning on editing a special issue for publication in an English language peer reviewed journal with contributions from various participants at the conference. Interested scientists are encouraged to contact one of the editors for further information.

\section{Pavel E. Tarasov}

Geography Department,

Moscow State University, Russia paveltarasov@hotmail.com 


\section{Last PACEE}

\section{CalendaR}

August 22 - August 27, 2002, Québec City, Canada 6th International Conference on Dendrochronology

Further information

http://www.cen.ulaval.ca/dendro2002/

August 29 - September 2, 2002, West London, UK Enviromental Catastrophes and Recoveries in the Holocene

Further information:

http://www.brunel.ac.uk/depts/geo/Catastrophes

Sept. 7 - Sept. 14, 2002, Grindelwald, Switzerland NCCR Climate Summer School

Further information:

MonikaWaelti: waelti@giub.unibe.ch

http://www.nccr-climate.unibe.ch/events/SummerScool/ general_information.htm
October 12 - October 13, 2002, Coastal Maine, USA CAPE Workshop: The Last Interglacial in the Arctic

Further information:

Gifford Miller: gmiller@colorado.edu

November 11 - November 14, 2002, Honolulu, Hawaii The Hadley Circulation: Present, Past and Future

Further information:

Contact e-mail: hadley@geo.umass.edu

http://www.geo.umass.edu/climate/hadley/home.html

December 9 - December 14, 2002, Davos, Switzerland Winter School: Wood Anatomy of Tree Rings

Further information:

Fritz Schweingruber: schweingruber@wsl.ch

\section{Tyler and Heineken Prizes awarded to paleo scientists:}

\section{Tyler Laureates Wallace S. Broecker and Tungsheng Liu}

The 2002 Tyler Prize for Environmental Achievement was awarded to Wallace S. Broecker to honor him for his pioneering discoveries using geological clues to understand the ocean's role in global climate change. Further, Broecker has been instrumental in developing the use of a wide range of geochemical tracers to describe basic biological, chemical and physical processes that govern the behavior of carbon dioxide in the oceans and the interactions of oceanic carbon dioxide with the atmosphere.

Tungsheng Liu was being honored for his pioneering contributions in recognizing and using terrestrial sediments to understand global environmental change. He has been a trailblazer in developing ways to measure paleoclimatic change over the last 2.5 million years through studies of loess, a windblown dust, that forms thick deposits over much of central China.

For more information see: http://www.usc.edu/admin/provost/tylerprize/02tyler

The Royal Netherlands Academy of Arts and Sciences has awarded the 2002 Dr A.H. Heineken Prize for Environmental Sciences to Lonnie G. Thompson

Lonnie Thompson is convinced that ice forms an excellent archive of the earth's past climate. This frozen history is located not only at the North and South Poles, but also in the tropics where the ice caps are in fact melting rapidly. Thompson was one of the first to realise that global warming poses a threat to a number of the world's ice archives. Partly because of this, gathering data is high on his list of priorities. Under extreme high altitude conditions, he has succeeded in collecting numerous ice cores. His ice samples come from all over the world: from Bolivia, Peru, China and a host of other locations.

For more information see: http://www.knaw.nl/heinekenprizes/pr_2002/02_05uk.htm 